\title{
A new Cyrtodactylus (Squamata: Gekkonidae) from Binh Thuan Province, southern Vietnam
}

\author{
Sabrina OSTROWSKI ${ }^{1}$, Minh Duc LE ${ }^{2}$, Hanh Thi NGO ${ }^{3}$, Cuong The PHAM ${ }^{4}$, \\ Trung My PHUNG ${ }^{5}$, Truong Quang NGUYEN ${ }^{6} \&$ Thomas ZIEGLER ${ }^{7, *}$ \\ ${ }^{1,7}$ Cologne Zoo, Riehler Str. 173, D-50735 Cologne, Germany. \\ ${ }^{1,7}$ Institute of Zoology, University of Cologne, Zülpicher Str. 47b, D-50674 Cologne, Germany. \\ ${ }^{2,3}$ Faculty of Environmental Sciences, University of Science, Vietnam National University, Hanoi, \\ 334 Nguyen Trai Road, Hanoi, Vietnam. \\ ${ }^{2,3}$ Central Institute for Natural Resources and Environmental Studies, Vietnam National University, \\ Hanoi, 19 Le Thanh Tong, Hanoi, Vietnam. \\ ${ }^{2}$ Department of Herpetology, American Museum of Natural History, Central Park West at 79th Street, \\ New York, New York 10024, USA. \\ ${ }^{4,6}$ Institute of Ecology and Biological Resources, Vietnam Academy of Science and Technology, \\ 18 Hoang Quoc Viet Road, Hanoi, Vietnam. \\ ${ }^{5}$ Institute of Applied Technology, 6 Tran Van On, Thu Dau Mot City, Binh Duong Province, Vietnam. \\ ${ }^{6}$ Graduate University of Science and Technology, Vietnam Academy of Science and Technology, \\ 18 Hoang Quoc Viet Road, Cau Giay, Hanoi, Vietnam. \\ *Corresponding author: ziegler@koelnerzoo.de \\ 1Email: sabrinaostrowski@mail.de \\ ${ }^{2}$ Email: le.duc.minh@hus.edu.vn \\ ${ }^{3}$ Email: ngohanhhus@gmail.com \\ ${ }^{4}$ Email: cuongiebr@gmail.com \\ ${ }^{5}$ Email: pmytrung@gmail.com \\ ${ }^{6}$ Email: nqt2@yahoo.com \\ ${ }^{1}$ urn:lsid:zoobank.org:author:30862A2D-E20E-4FC2-B81C-A7E5FBF3E1C7
${ }^{2}$ urn:lsid:zoobank.org:author:785D605E-6A6F-4A67-BD18-7F40F426FC2C
${ }^{3}$ urn:1sid:zoobank.org:author:6B87B552-B68B-46A7-8678-4E6EAE01428A
${ }^{4}$ urn:Isid:zoobank.org:author:9ECAF214-1F25-4B1A-8BEA-701B218E22BD
${ }^{5}$ urn:1sid:zoobank.org:author:F05DF764-A42C-4993-B570-04E351E31A7D
${ }^{6}$ urn:lsid:zoobank.org:author:822872A6-1C40-461F-AA0B-6A20EE06ADBA
${ }^{7}$ urn:1sid:zoobank.org:author:5716DB92-5FF8-4776-ACC5-BF6FA8C2E1BB
}

Abstract. We describe a new species of Cyrtodactylus on the basis of two specimens collected from Ta Kou Nature Reserve, Binh Thuan Province, southern Vietnam. Cyrtodactylus chungi sp. nov. is distinguished from the remaining Indochinese bent-toed geckos by a combination of the following characters: relatively small body size (SVL up to $68.5 \mathrm{~mm}$ ); a continuous neckband; 5 or 6 irregular transverse dorsal bands; 11 or 12 bands on original tail; keeled tubercles present on dorsum, posterior limbs and tail; 17 or 18 irregular dorsal tubercle rows; 30 or 31 ventral scale rows; ventrolateral skin 
folds indistinct; an angular series of seven precloacal pores in male and six pitted, enlarged precloacal scales in female, each series separated by a diastema of undifferentiated scales from 4-6 enlarged, poreless femoral scales; median subcaudals slightly enlarged; 17-20 subdigital lamellae under the fourth toe. Based on molecular analyses of the fragment of mitochondrial gene cytochrome c oxidase subunit I (COI), the new species is recovered as the sister taxon to Cyrtodactylus cattienensis s. str. with a genetic divergence of more than $9 \%$. In phylogenetic analyses, the new species is recovered as a member of the Cyrtodactylus irregularis species group.

Keywords. Cyrtodactylus chungi sp. nov., molecular phylogeny, taxonomy, Ta Kou Mountain, COI gene.

Ostrowski S., Le M.D., Ngo H.T., Pham C.T., Phung T.M., Nguyen T.Q. \& Ziegler T. 2021. A new Cyrtodactylus (Squamata: Gekkonidae) from Binh Thuan Province, southern Vietnam. European Journal of Taxonomy 731: 47-70. https://doi.org/10.5852/ejt.2021.731.1203

\section{Introduction}

The gekkonid genus Cyrtodactylus Gray, 1827 is by far the most speciose with many new species being described every year (Grismer et al. 2018; Murdoch et al. 2019). A total of 305 species have been recognized to date (Uetz et al. 2020). Vietnam has been a hotspot of new discoveries with 43 recorded species (Nazarov et al. 2012; Luu et al. 2017; Ostrowski et al. 2020; Uetz et al. 2020). Gymnodactylus peguensis var. irregularis was described by Smith (1921a) from an open pine forest at Camly in the Langbian Plateau, Vietnam. Nazarov et al. (2008) suggested that this and all other allied species belonged to a species complex (Nazarov et al. 2012; Pauwels et al. 2018). The C. irregularis complex has recently been the subject of numerous morphological and molecular studies. So far, 20 species have been described along with several additional populations whose taxonomic status is unresolved or still unknown (S.N. Nguyen et al. 2017; Pauwels et al. 2018; Ostrowski et al. 2020; Uetz et al. 2020). Thus, Neang et al. (2020) described C. phnomchiensis, the only member of the C. irregularis complex, which occurs west of the Mekong River in Kampong Thom Province, Cambodia.

S.N. Nguyen et al. (2017) investigated the effectiveness of DNA barcoding based on the COI gene using 164 samples of Vietnamese bent-toed geckos within the C. irregularis complex. They discovered eleven unnamed lineages from different localities, including the population analyzed in this study. Based on an integrative taxonomic approach, viz. combining morphological and molecular data, we herein clarify the status of the Cyrtodactylus population from Ta Kou, Binh Thuan Province.

\section{Material and methods}

\section{Sampling}

Field surveys were conducted in Ta Kou Nature Reserve, Ham Thuan Nam District, Binh Thuan Province, southern Vietnam in June 2017 (Fig. 1). Specimens were euthanized in a closed vessel with a piece of cotton wool containing ethyl acetate (Simmons 2002), fixed in $80 \%$ ethanol and subsequently stored in $70 \%$ ethanol. Specimens were deposited in the collections of the Institute of Ecology and Biological Resources (IEBR), Hanoi, Vietnam.

\section{Molecular data and phylogenetic analyses}

All taxa of the Cyrtodactylus irregularis species complex were included in our analyses. Available sequences of the species were obtained from GenBank. Two new samples from a population in Ta Kou Mountain, Binh Thuan Province of southern Vietnam (IEBR 4581 and 4582) were included in the analysis. Two species, C. spelaeus Nazarov, Poyakov, Orlov, Nguyen, Milto, Martynov, Konstantinov \& 


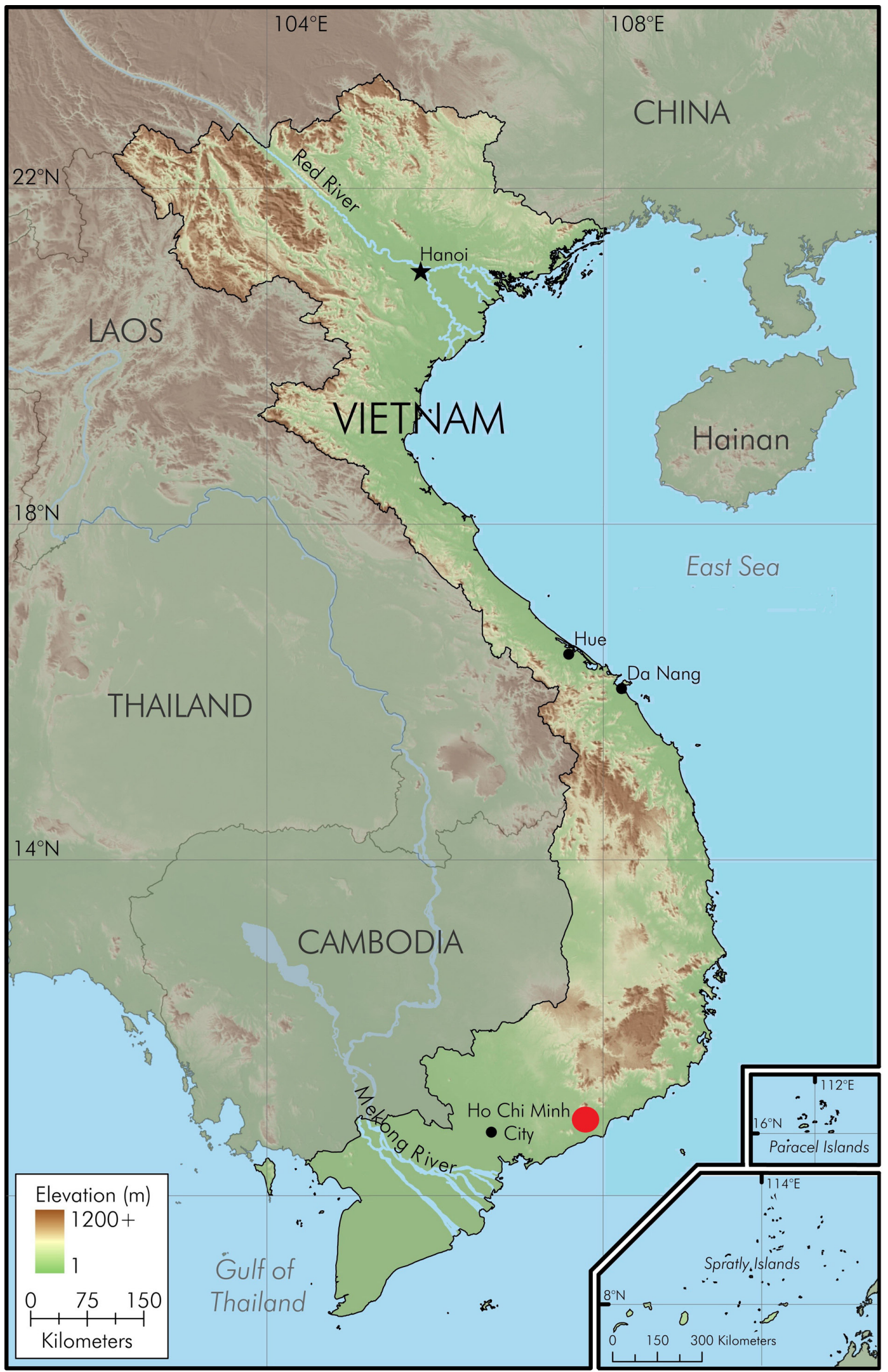

Fig. 1. Map of Vietnam showing the type locality of Cyrtodactylus chungi sp. nov. in Binh Thuan Province. 
Chulisov, 2014 and C. wayakonei Nguyen, Kingsada, Rösler, Auer \& Ziegler, 2010, were used as an outgroup based on the results from Luu et al. (2016).

DNA was extracted using a DNeasy Blood and Tissue kit (Qiagen, Germany) following the manufacturer's instruction. Extracted DNA was amplified by HotStar Taq PCR mastermix (Qiagen, Germany) with $21 \mu 1$ volume (10 $\mu 1$ of mastermix, $5 \mu 1$ of water, $2 \mu 1$ of each primer at $10 \mathrm{pmol} / \mathrm{ml}$ and $2 \mu \mathrm{l}$ of DNA). PCR condition was: $95^{\circ} \mathrm{C}$ for 15 minutes to active the taq; with 40 cycles at $95^{\circ} \mathrm{C}$ for $30 \mathrm{~s}, 45^{\circ} \mathrm{C}$ for $45 \mathrm{~s}, 72^{\circ} \mathrm{C}$ for $60 \mathrm{~s}$; and the final extension at $72^{\circ} \mathrm{C}$ for 6 minutes. A fragment of the mitochondrial gene, cytochrome c oxidase subunit I (COI), was amplified using the primer pair VF1-d (5'-TTCTCAACCAACCACAARGAYATYGG-3') and VR1-d (5'-TAGACTTCTGGGTGGCCRAARAAYCA-3)' (Ivanova et al. 2006).

PCR products were visualized using electrophoresis through a $2 \%$ low melting-point agarose gel stained with ethidium bromide. Successful amplifications were purified to eliminate PCR components using GeneJET $^{\text {TM }}$ PCR Purification kit (ThermoFisher Scientific, Lithuania). Purified PCR products were sent to FirstBase (Malaysia) for sequencing.

After sequences were aligned by Clustal X ver. 2 (Thompson et al. 1997), data were analyzed using maximum parsimony (MP) as implemented in PAUP*4.0b10 (Swofford 2002), maximum likelihood (ML) in IQ-TREE ver. 1.6.7.1 (Nguyen et al. 2015), and Bayesian inference (BI) in MrBayes ver. 3.2 (Ronquist et al.2012). For MP analysis, heuristic analysis was conducted with 100 random taxon addition replicates using tree-bisection and reconnection (TBR) branch swapping algorithm, with no upper limit set for the maximum number of trees saved. Bootstrap support (BP) was calculated using 1000 pseudoreplicates and 100 random taxon addition replicates. $\mathrm{BP} \geq 70$ was considered strong support for the clade (Hillis \& Bull 1993). All characters were equally weighted and unordered. For the maximum likelihood (ML) analysis, the analysis was run with a single model and 10000 ultrafast bootstrap replications using the command iqtree - s matrix.nex $-\mathrm{m}$ TIM $+\mathrm{I}+\mathrm{G}-\mathrm{bb} 10000$. Ultrafast bootstrap $\geq 95 \%$ was regarded as significant (Nguyen et al. 2015) The optimal model for nucleotide evolution was determined using Modeltest ver. 3.7 (Posada \& Crandall 1998).

For BI analysis, we used the optimal model on an unpartitioned data set determined by Modeltest with parameters estimated by MrBayes ver. 3.2.1. Two independent analyses with four Markov chains (one cold and three heated) were run simultaneously for 10 million generations with a random starting tree and sampled every 1000 generations. Log-likelihood scores of sample points were plotted against generation time to determine stationarity of Markov chains. Trees generated before log-likelihood scores reached stationarity were discarded from the final analyses using the burn-in function. The posterior probability (PP) values for all clades in the final majority rule consensus tree were provided. PP $\geq 95 \%$ were deemed strong support for a clade (Ronquist et al. 2012). The optimal model for nucleotide evolution was set to $\mathrm{TIM}+\mathrm{I}+\mathrm{G}$ for $\mathrm{ML}$ and combined Bayesian analyses as selected by Modeltest ver. 3.7. The cutoff point for the burn-in function was set to 30 in the Bayesian analysis, as $-\ln L$ scores reached stationarity after 30000 generations in both runs. Uncorrected pairwise divergences were calculated in PAUP*4.0b10.

\section{Morphological characters}

Measurements were taken with a digital calliper to the nearest $0.1 \mathrm{~mm}$.
Abbreviations
$\mathrm{AG}=$ trunk length or axilla-groin distance, from posterior edge of forelimb insertion to anterior edge of hindlimb insertion
ED $\quad=$ ear diameter, measured vertically 


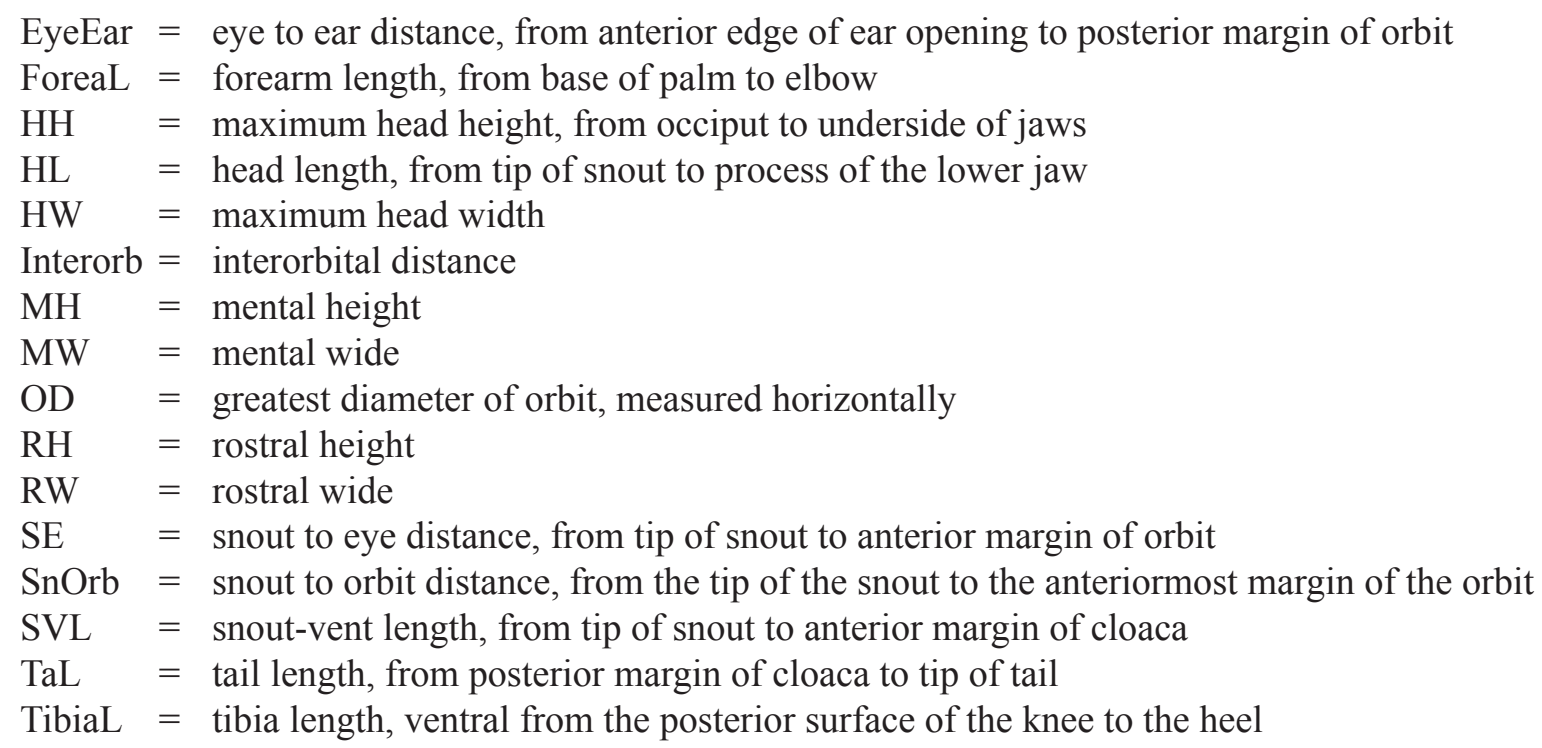

\section{Scale counts}

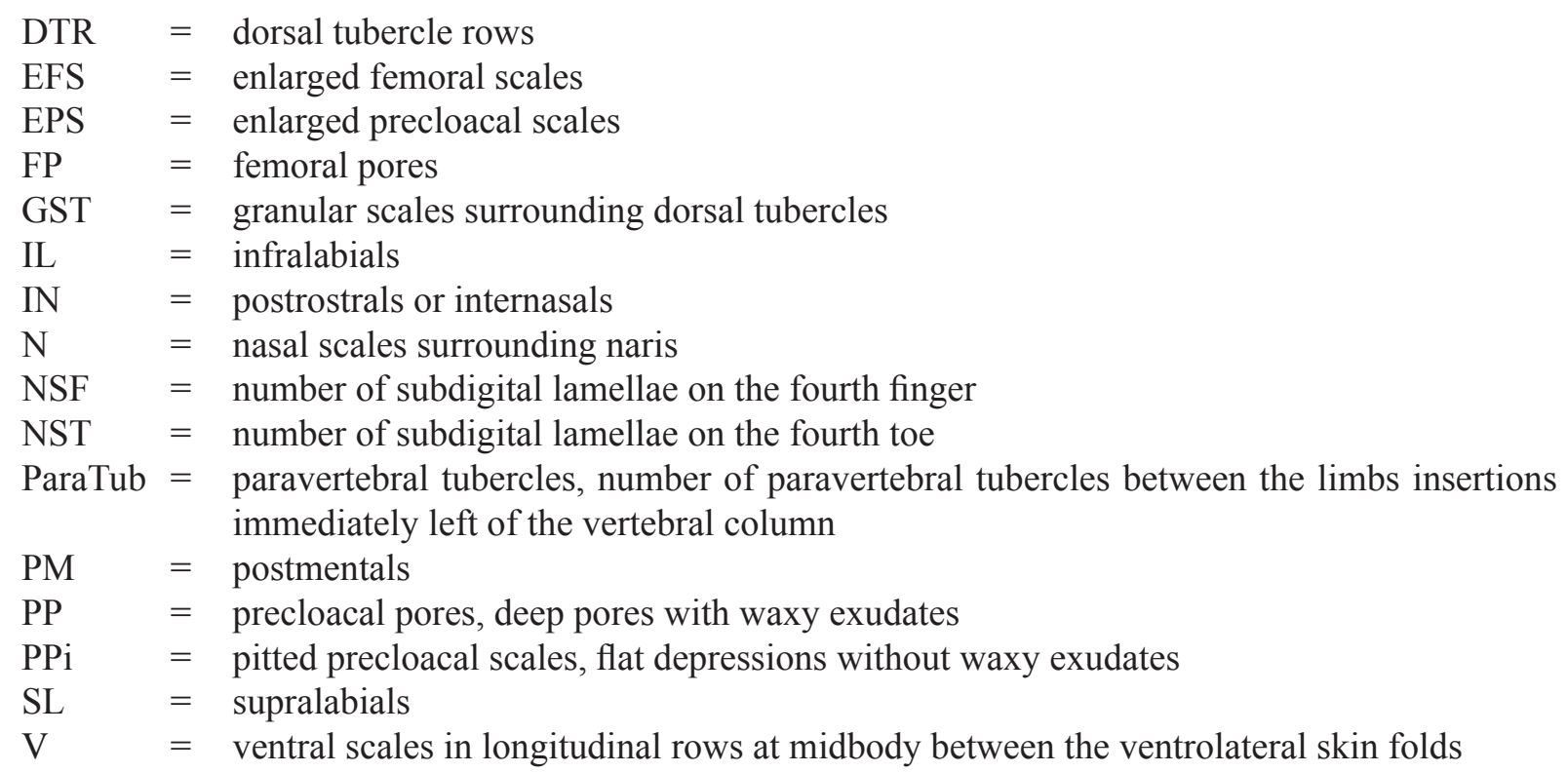

Bilateral scale counts were given as left/right.

\section{Results}

Based on the molecular data, Cyrtodactylus chungi sp. nov. is placed in a clade with $C$. cattienensis s. str. (Fig. 2). Besides the many similarities like the closed neck band, an X-shaped shoulder band, 5 or 6 irregular transverse dorsal bands (vs 4-6) and 11 or 12 transverse bands on the tail (vs 4-12) it was found that there are still distinct differences. The new species can be distinguished from $C$. cattienensis s. str. by a median row of slightly enlarged subcaudal scales, dark brown transversal bands of the tail narrower than the light brown spaces (vs wider transversal bands than the light spaces), by the presence of pitted, enlarged precloacal scales in the female (6 vs absence), by the higher number of tubercle rows on the tail (6 vs 4), which are strongly to slightly keeled (vs anteriorly keeled tubercle) and by the relatively strongly keeled tubercles on the hindlimbs (vs smooth tubercles). 


\section{Phylogenetic analyses}

The alignment contained no gaps and the final matrix consisted of 652 aligned characters. Of these, 244 were parsimony informative. The MP analysis of the dataset recovered a single most parsimonious tree with 1328 steps $(\mathrm{CI}=0.35$; $\mathrm{RI}=0.65)$. The topology derived from $\mathrm{BI}$ was largely similar to those of Luu et al. (2017) and Pauwels et al. (2018). Although the phylogenetic tree supported by Pauwels et al. (2018) is better resolved, most of the deep nodes in this study are insignificantly supported. There are a few discrepancies between our phylogenetic hypothesis and that of Pauwels et al. (2018), in particular, the position of Cyrtodactylus phuocbinhensis Nguyen, Le, Tran, Orlov, Lathrop, Macculoch, Le, Jin, Nguyen, Nguyen, Hoang, Che, Murphy \& Zhang, 2013. This species was supported as the sister species to C. sangi Pauwels, Nazarov, Bobrov \& Poyarkov, $2018+$ C. cattienensis Geissler, Nazarov, Orlov, Böhme, Phung, Nguyen \& Ziegler, 2009 in our BI and ML analyses (Fig. 2), but it was shown as the basal taxon of a large clade, including C. kingsadai Ziegler, Phung, Le \& Nguyen, 2013, C. taynguyenensis Nguyen, Le, Tran, Orlov, Lathrop Macculoch, Le, Jin, Nguyen, Nguyen, Hoang, Che, Murphy \& Zhang, 2013, C. takouensis Ngo \& Bauer, 2008 among others with also high statistical values from both BI and ML in Pauwels et al. (2018: fig. 2). In our study, however, we incorporated more species and used different outgroups than did in Pauwels et al. (2018), and these changes might have caused the differences.

The phylogenetic results show that the new species from Ta Kou Mountain, Binh Dinh Province was recovered as the sister taxon to $C$. cattienensis $\mathrm{s}$. str. with a high statistical support (all equal to 100\%) in all analyses (Fig. 2). In terms of genetic divergences, the new species is separated from C. cattienensis s. str. with uncorrected p-distance of 9.4-9.5\%. It is also significantly divergent from other species within the $C$. irregularis species group with the pairwise divergence of $14.2-18.3 \%$. Genetic divergences between other species in the group are shown in the distance matrix (Supplementary File 1).

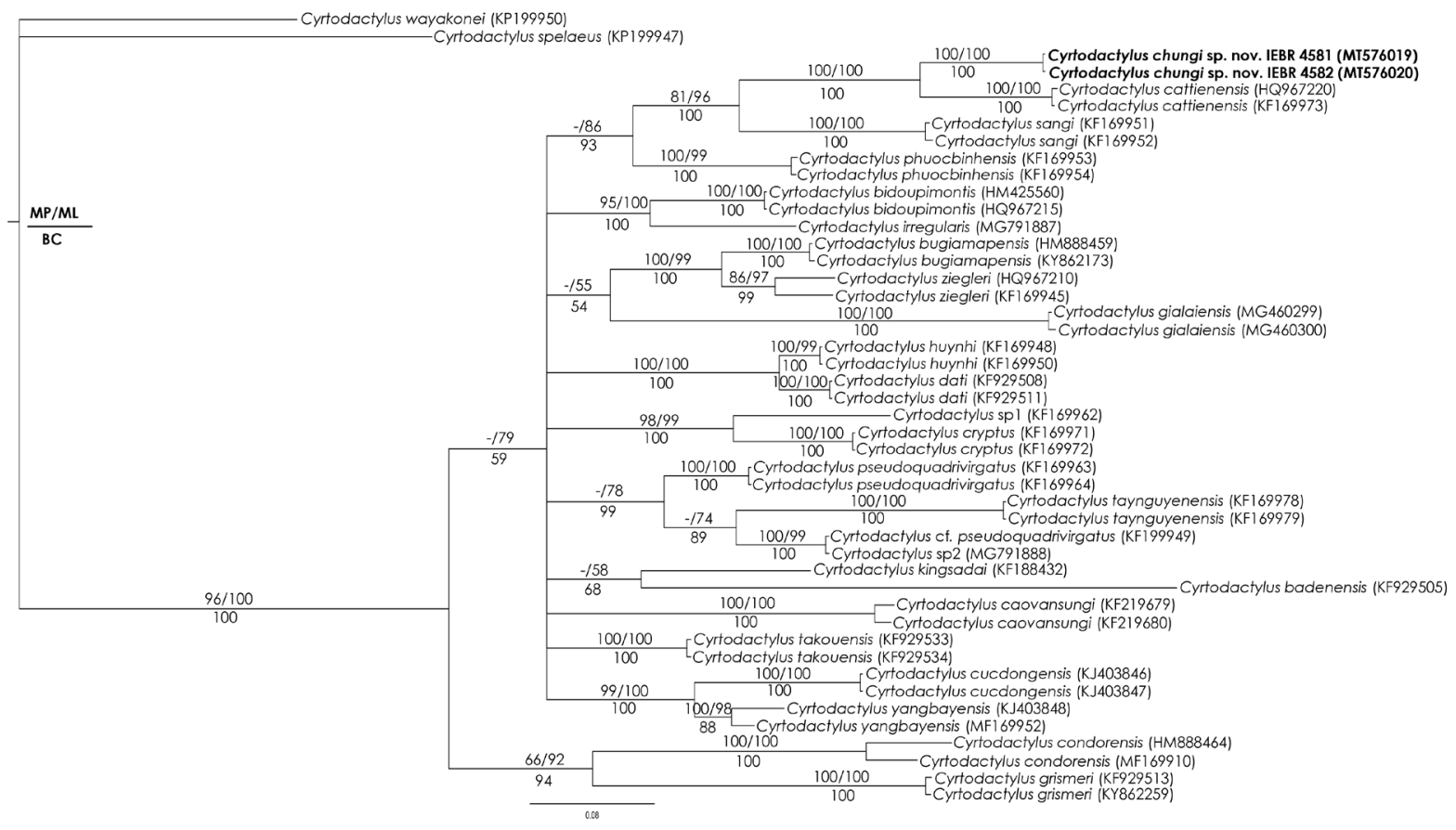

Fig. 2. Phylogram based on the Bayesian analysis. Number above and below branches are MP/ML bootstrap values and Bayesian posterior probabilities (>50\%), respectively. 


\title{
Morphological analyses
}

\author{
Class Reptilia Laurenti, 1768 \\ Order Squamata Oppel, 1811 \\ Family Gekkonidae Gray, 1825 \\ Subfamily Gekkoninae Gray, 1825 \\ Genus Cyrtodactylus Gray, 1827 \\ Cyrtodactylus chungi sp. nov. \\ urn:1sid:zoobank.org:act:C3B181E8-F9D3-4344-AD20-28765D1BA0B2
}

Figs 3-8

\section{Diagnosis}

The new species can be distinguished from other members of the genus Cyrtodactylus by a combination of the following characters (Table 1): relatively small body size (SVL up to $68.5 \mathrm{~mm}$ ); a continuous neckband; 5 or 6 irregular transverse dorsal bands; 11 or 12 bands on original tail; keeled tubercles present on dorsum, posterior limbs and tail; 17 or 18 irregular dorsal tubercle rows; 30 or 31 ventral scale rows; ventrolateral skin folds indistinct; an angular series of seven precloacal pores in male and six pitted, enlarged precloacal scales in female, each series separated by a diastema of undifferentiated scales from 4-6 enlarged, poreless femoral scales; median subcaudals slightly enlarged; 17-20 subdigital lamellae under the fourth toe.

\section{Etymology}

Specific epithet 'chungi' is in honor of Prof. Dr Ngo Dac Chung, College of Education, Hue University, in recognition of his outstanding contributions to training of many herpetologist generations from Hue University. For the common names we suggest Chung's Bent-toed Gecko (English) and Thạch sùng ngón chứng (Vietnamese).

\section{Type material (Figs 3-8)}

\section{Holotype}

VIETNAM - 3 ; Southern Vietnam, Ham Thuan Nam District, Binh Thuan Province, Ta Kou Nature Reserve; $10^{\circ} 48.868^{\prime}$ N, 10753.523' E; 424 m a.s.1.; 20 Jun. 2017; T.M. Phung leg.; Field No. BT2017.1; sequence with GenBank accession number MT576019; IEBR 4581.

\section{Paratype}

VIETNAM • 1 क ; same collection data as for holotype; Field No. BT2017.2; sequence with GenBank accession number MT576020; IEBR 4582.

\section{Description of holotype}

Adult male, snout-vent length (SVL) $66.6 \mathrm{~mm}$; tail length (TL) $62.7 \mathrm{~mm}(45.1 \mathrm{~mm}$ regenerated); head distinct from neck, relatively long (HL: $20.1 \mathrm{~mm}$; HL/SVL ratio 0.32 ), HW $13.3 \mathrm{~mm}$ (HW/ HL ratio 0.66$), \mathrm{HH} 7.8 \mathrm{~mm}(\mathrm{HH} / \mathrm{HL}$ ratio 0.4$)$; loreal region slightly bulged; snout elongated and rounded (SE: 7.6; SE/HL ratio 0.38 ); eye diameter $4.4 \mathrm{~mm}$, more than half of snout-eye distance (OD/SE ratio 0.58); median snout scales small and rounded; eyes relatively small compared to head (OD/HL ratio 0.22); anterior supraciliaries large and rounded, posterior supraciliaries small and tapered; ear openings relatively small (ED: $0.75 \mathrm{~mm}$; ED/HL ratio 0.04 ), vertical and oval in shape; eye to ear distance slightly longer than eye diameter (EyeEar/ED ratio 1.39); rostral wider than high (RH: $1.65 \mathrm{~mm}$; RW: $3.3 \mathrm{~mm}$; RW/RH ratio 2), with an inverse, Y-shaped median suture, surrounded by first supralabial, two nostrils, two supranasals and internasal; lateral nostrils elongated, oval and 
Table 1. Measurements (in mm) and morphological characters of type series of Cyrtodactylus chungi sp. nov. $*=$ regenerated or broken tail; bilateral meristic characters are given as left/right.

\begin{tabular}{|c|c|c|}
\hline characters & $\begin{array}{l}\text { IEBR } 4581 \\
\text { (holotype) }\end{array}$ & $\begin{array}{l}\text { IEBR } 4582 \\
\text { (paratype) }\end{array}$ \\
\hline Sex & $\hat{0}$ & q \\
\hline SVL & 66.6 & 68.55 \\
\hline TL & $62.75^{*}\left(45.1^{*}\right)$ & $82.15^{*}$ \\
\hline $\mathrm{AG}$ & 27.5 & 28.8 \\
\hline ForeaL & 10.2 & 10.2 \\
\hline TibiaL & 11.2 & 11.2 \\
\hline $\mathrm{HH}$ & 7.8 & 7.7 \\
\hline HL & 20.1 & 20.4 \\
\hline HW & 13.3 & 12.4 \\
\hline OD & 4.4 & 4.4 \\
\hline EyeEar & 6.1 & 5.8 \\
\hline SE & 7.6 & 27.5 \\
\hline SnOrb & 4.3 & 4.75 \\
\hline InterOrb & 4.6 & 5.35 \\
\hline ED & 0.75 & 0.75 \\
\hline $\mathrm{RH}$ & 1.65 & 1.35 \\
\hline RW & 3.3 & 3.4 \\
\hline MH & 1.7 & 2.0 \\
\hline MW & 2.6 & 2.7 \\
\hline SL & $12 / 11$ & $12 / 11$ \\
\hline IL & $9 / 9$ & $8 / 9$ \\
\hline $\mathrm{N}$ & $4 / 5$ & $4 / 4$ \\
\hline $\mathrm{IN}$ & 1 & 3 \\
\hline PM & 2 & 2 \\
\hline DTR & 18 & 17 \\
\hline ParaTub & 24 & 27 \\
\hline GST & $9-11$ & $10-11$ \\
\hline V & 31 & 30 \\
\hline PPi/PP & $0 / 7$ & $6 / 0$ \\
\hline EPS & 45 & 41 \\
\hline FP & 0 & 0 \\
\hline EFS & $6 / 4$ & $6 / 6$ \\
\hline $\mathrm{NSF}$ & $16 / 15$ & $18 / 18$ \\
\hline NST & $17 / 17$ & $20 / 20$ \\
\hline
\end{tabular}


surrounded by rostral, first supralabial, three postnasals and one supranasal; supranasals separated by one internasal; eye separated from supralabials by 3 or 4 scale rows; mental triangular, wider than high (MW: $1.75 \mathrm{~mm}$; MH $2.6 \mathrm{~mm}$; MW/MH ratio 1.49), surrounded by first two infralabials and posteriomedially by postmentals; supralabials 10/9; infralabials $9 / 9$; body slender and short (AG/SVL ratio 0.41); ventrolateral skin folds not developed; dorsal scales granular, heterogeneous in shape and size; dorsal tubercles present in posterior part of head, extremities, dorsum and first third of tail; postocular tubercles irregularly distributed, rounded, flat and about three times size of surrounding granular scales; median dorsal tubercles about five times as large as granular scales, oval, and not keeled; posterior dorsal tubercles keeled and on sacral region very strongly keeled up to base of tail; 18 irregular transversal dorsal tubercle rows; 24 paravertebral tubercles; each tubercle surrounded by 9 or 10 granular scales; ventrals smooth, oval and slightly imbricate, in 31 longitudinal rows; gular scales homogeneous; dorsal surfaces of upper and lower arms without tubercles, but occasionally enlarged granular scales; left thigh with series of 6 enlarged femoral scales separated by diastema of 6 smaller scales from precloacal scales; right thigh with series of 3 enlarged femoral scales separated by diastema of 8 smaller scales from precloacal scales and single enlarged femoral scale distally; no femoral pores; 45 enlarged precloacal scales arranged in diamond shape, with angled series of 7 pore-bearing scales ( 3 right, 1 angled, 3 left); 15 posteriorly enlarged scales and 21 anteriorly enlarged scales; two postcloacal tubercles on each side; scales on palms and soles rounded to oval, smooth and arched; fore- and hindlimbs moderately long (ForeaL/SVL ratio 0.15; Tibia/SVL ratio 0.17 ) relatively narrow; toes and fingers narrow and curved at interphalangeal joint; slightly transparent, pointed and curved claws, bordered ventrally by large lamella and dorsally by small, narrow scale; subdigital lamellae proximally larger, widened and merge basally into smaller scales of palm and sole surfaces; distal lamellae smaller, more elongated and distally increasingly imbricate; right fourth finger with 15 subdigital lamellae (6 proximal, 9 distal); left fourth finger with 16 subdigital lamellae (5 proximal, 11 distal); right and left fourth toe with 17 subdigital lamellae each (6 proximal, 11 distal); base of tail with small granular supracaudals and strongly keeled, rounded tubercles; last two thirds of tail regenerated, scales heterogeneously arranged and shaped; tubercles of original part arranged in 6 transverse rows (8/-/4/4/4/4) in a distance of 6-7 granular scale rows; tubercles slightly keeled; subcaudals of original part oval, rounded and imbricate; median subcaudals about two to three times larger than the lateral scales, but not transversely enlarged, or arranged in definable rows.

\section{Coloration in preservative (Figs 5-8)}

Ground color of head, neck, limbs and tail grey to light brown; dorsal surface of head brown with irregular, small, dark brown spots; two larger dark brown blotches located in posterior interorbital area and two other dark brown blotches in occiput area; skin above eyes dark grey, blue to black; rostral dark brown; supralabials and infralabials also brown, turning to cream at adjacent areas; a distinct dark brown stripe in loreal region, reaching to third supralabial; nuchal loop dark brown, in V-shape, extending from posterior corner of eye to the neck, edged in light grey; tubercles on head, limbs, dorsum and tail light to dark brown; tubercles on lateral skin fold white to gray; dorsal surfaces of limbs with small, irregularly distributed, dark brown spots; dorsal surface of toes and fingers dark brown spotted with light grey; dorsum with 5 irregular transverse dark brown bands; first band over the shoulder region, $\mathrm{X}$-shaped; dark and light brown spots present between transverse bands and on flanks; ventral scales of body light grey to cream; lateral sides of head, below postocular stripe, and ventrolateral margins of flanks slightly white to cream; anterior part of tail with two transverse, dark brown bands dorsally with dark brown spots in interspaces; dark, transverse dorsal bands separated from underside of tail by light brown, whitish spotted sides of tail; tail light grey to cream ventrally and marbled brown on the original part; regenerated part of tail grey to light brown, marbled. 


\section{Coloration in life}

Ground color of dorsal surface of head, limbs and dorsum bright-yellow; transverse body and tail bands darker; lateral head and belly with bright-yellow spots; marbling of surface of limbs darker; ventral surface white to light blue (Figs 3-4).

\section{Sexual dimorphism and variation}

The morphological characteristics of the female IEBR 4582 correspond well with the holotype (IEBR 4581) and differ only in a few details. The female has some slightly keeled tubercles on the dorsal surface of the forelimbs. Dorsal tubercles are keeled from the posterior insertion of the forelimbs. The two supranasals are separated by two internasals. Another internasal is inserted between the rostral and the two internasals. Two inverse sutures are X-shaped from the lower edges of the internasal and do not form a median suture. The tail is original. The median subcaudals are about twice as large as the supracaudals and extend to the tip of the tail. The two dark brown spots of the occiput are longer and larger. The neck band is also V-shaped but pointed posteriorly. The dorsal surfaces of the forearms and hindlimbs with fine, irregular, transverse stripes. Dorsum with 6 transverse, irregular bands. The first band, between the insertion of the forelimbs, is clearly X-shaped over the shoulder region. Between the neck band and the first body band is an oval, dark brown spot. The dorsal tubercles are clearly lighter. The dorsal side of the tail bears 11-12 transverse, dark brown bands, which completely enclose only the last third. Between these bands are irregular, fine, light brown to brown stripes and dots. The first two thirds of the underside of the tail are marbled light grey to brown. The last third resembles the dorsal side.

\section{Comparison}

We compared the new species with its 19 congeners from the Cyrtodactylus irregularis complex based on an examination of specimens (Table 2) and data obtained from the literature (Smith 1921a, 1921b; Ziegler et al. 2002, 2013; Heidrich et al. 2007; Orlov et al. 2007; Nazarov et al. 2008. 2012; Ngo \& Bauer 2008; Rösler et al. 2008; Geissler et al. 2009; Ngo \& Chan 2010; Ngo 2013; Nguyen et al. 2013; Schneider et al. 2014; Luu et al. 2017; Pauwels et al. 2018; Neang et al. 2020; Ostrowski et al. 2020). The new species can be distinguished from all other Cyrtodactylus species from Vietnam by morphological characteristics (see Table 3).

In comparison with the species from the C. irregularis complex Cyrtodactylus chungi sp. nov. is distinguished from C. caovansungi Orlov, Nguyen, Nazarov, Ananjeva \& Nguyen, 2007, C. kingsadai Ziegler, Phung, Le \& Nguyen, 2013, C. takouensis Ngo \& Bauer, 2008 and C. yangbayensis Ngo \& Chan, 2010 by the absence of transversely enlarged subcaudals.

The new species can be distinguished from C. cryptus Heidrich, Rösler, Vu, Böhme \& Ziegler, 2007, C. gialaiensis Luu, Tran, Nguyen, Le \& Ziegler, 2017, C. pseudoquadrivirgatus Rösler, Nguyen, Vu, Ngo \& Ziegler 2008 and C. taynguyenensis Nguyen, Le, Tran, Orlov, Lathrop Macculoch, Le, Jin, Nguyen, Nguyen, Hoang, Che, Murphy \& Zhang, 2013 by the presence of enlarged femoral scales.

The new species can be distinguished from C. bidoupimontis Nazarov, Poyarkov, Orlov, Phung, Nguyen, Hoang \& Ziegler, 2012 by its smaller size (SVL of 66.6-68.5 vs 74.0-86.3 mm), fewer ventral scale rows (30-31 vs 38-43) and enlarged femoral scales (4-6 vs 8-10), more precloacal pores in the male (7 vs 4-6), the presence of 6 pitted precloacal scales in the female (vs absence) and by the different dorsal color patter (irregular transversal bands vs irregular transversal bands with light borders).

Cyrtodactylus chungi sp. nov. differs from C. bugiamapensis Nazarov, Poyarkov, Orlov, Phung, Nguyen, Hoang \& Ziegler, 2012 by having fewer ventral scale rows (30-31 vs 36-46) and enlarged femoral scales (4-6 vs 6-8), and by the different dorsal color pattern (irregular transversal bands vs round spots forming irregular transverse bands). 

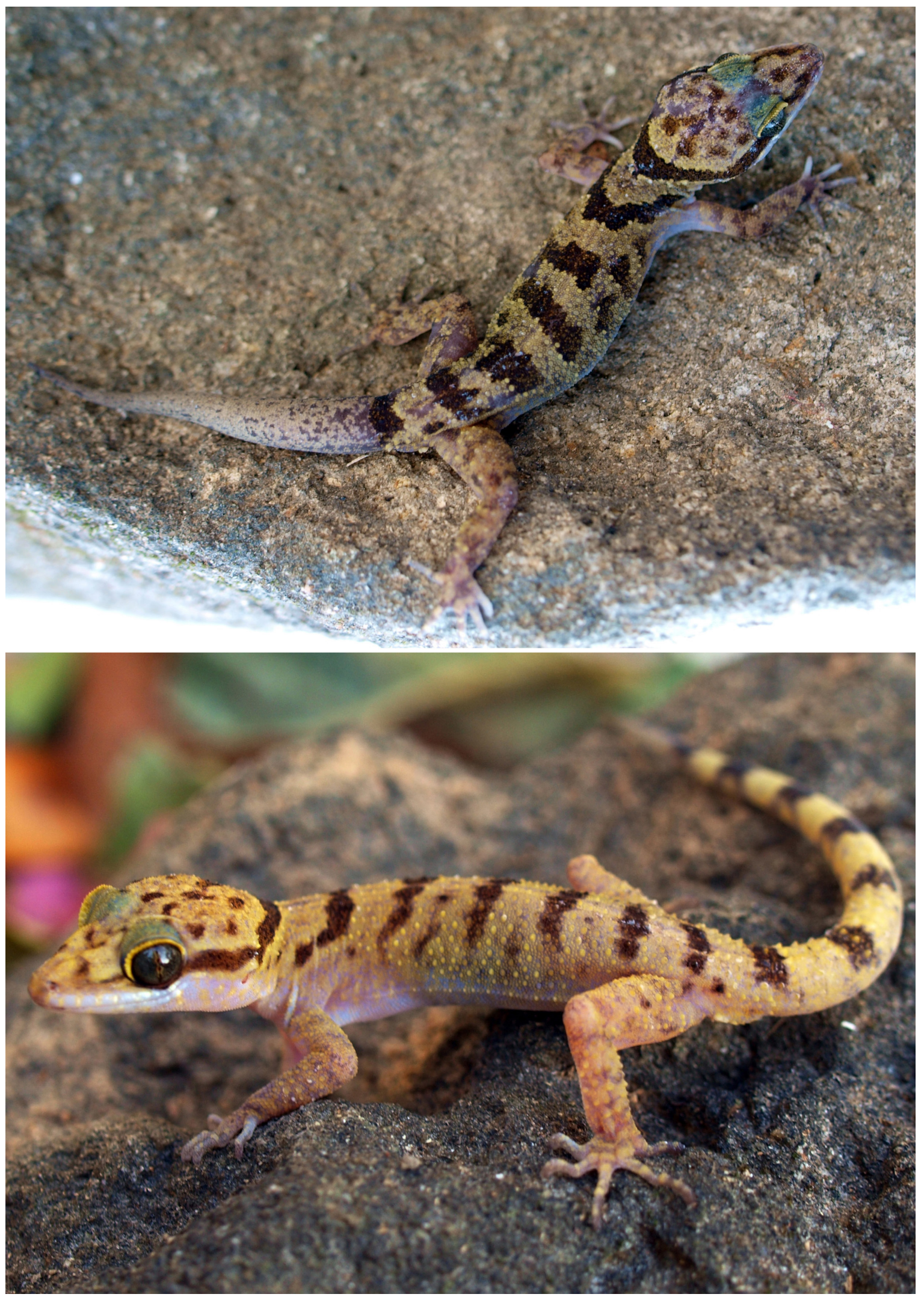

Fig. 3. Cyrtodactylus chungi sp. nov. in life. Top: holotype, $\lesssim$ (IEBR 4581). Bottom: paratype, $q$ (IEBR 4582). Photos T.M. Phung. 


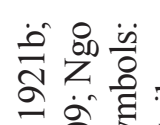

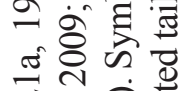

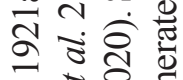

ธิ ฮิ

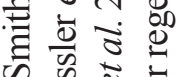

की

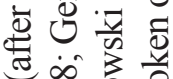

बके है है

造兽

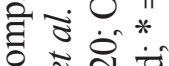

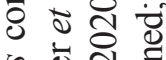

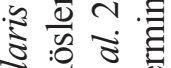

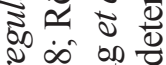

ơ

ن 实芯

幽

फ्पे

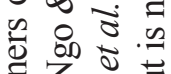

焉范

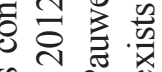

$\stackrel{0}{*} \cong$

च 응

完芯芯

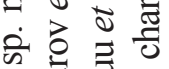

क

艺莳

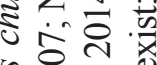

유휴

స్త

ठ

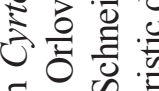

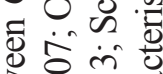

造穴芒芯

จ

ฮี ฮ

률 仓

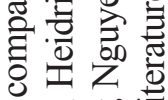

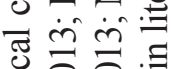
해유휴. ㅇํㅇ용 릉 율 ¿ 근 卷焉

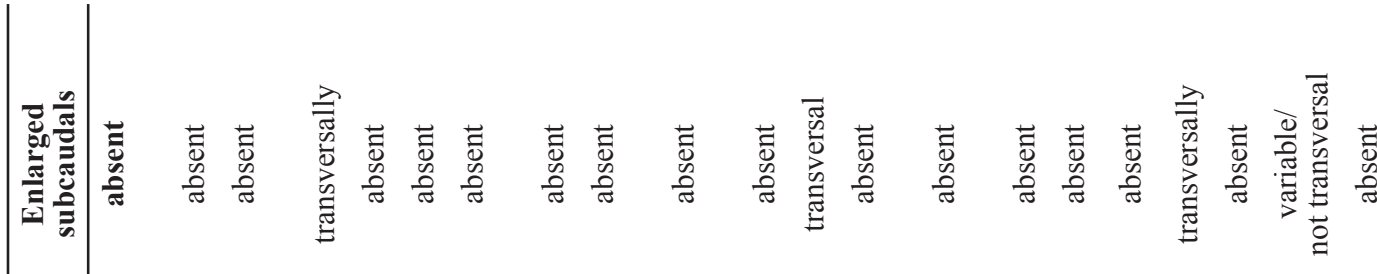

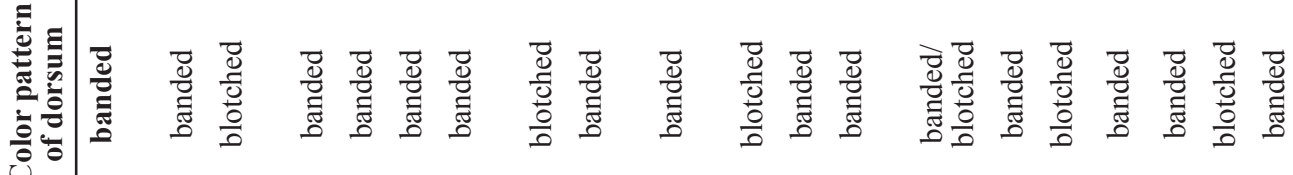

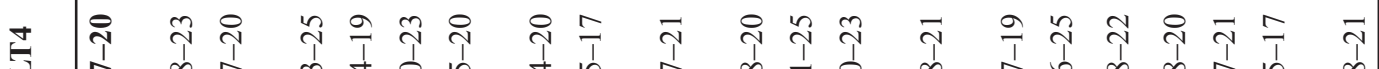

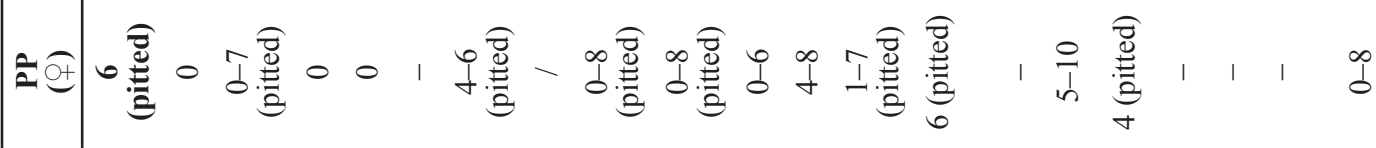

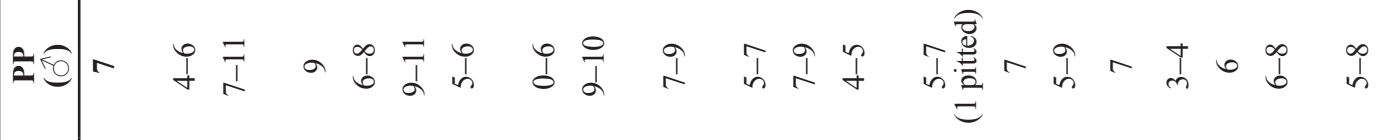

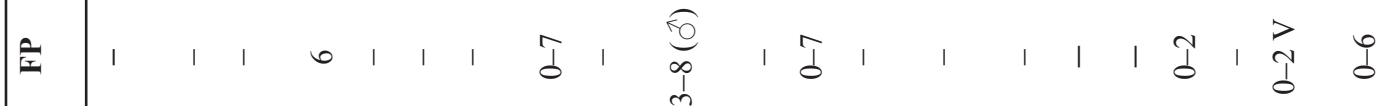

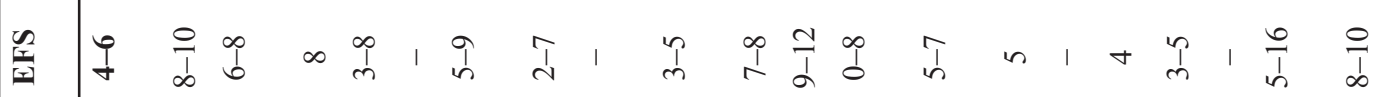

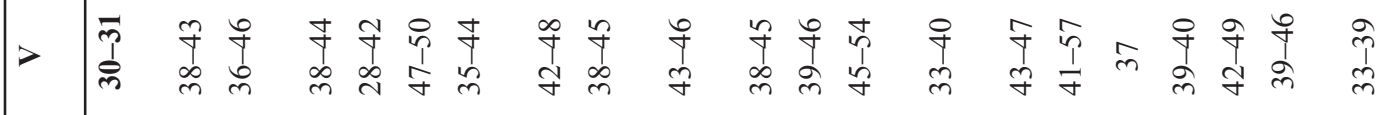

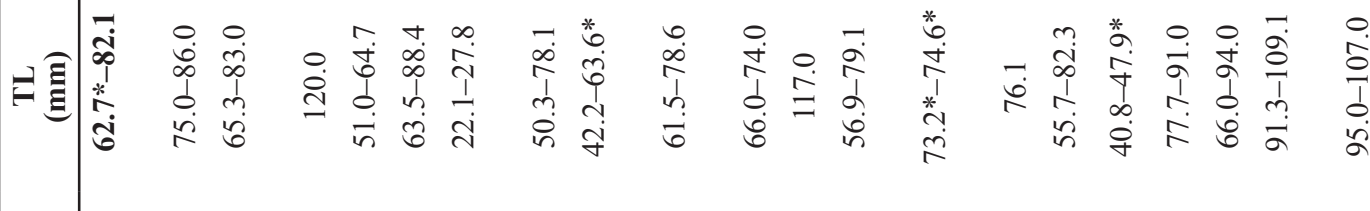

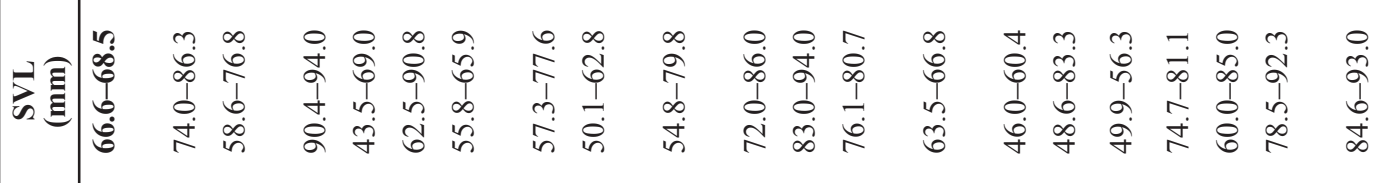

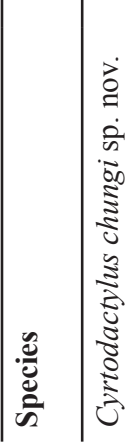

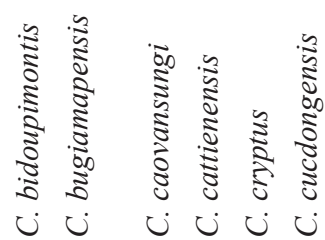


OSTROWSKI S. et al., A new Cyrtodactylus from southern Vietnam

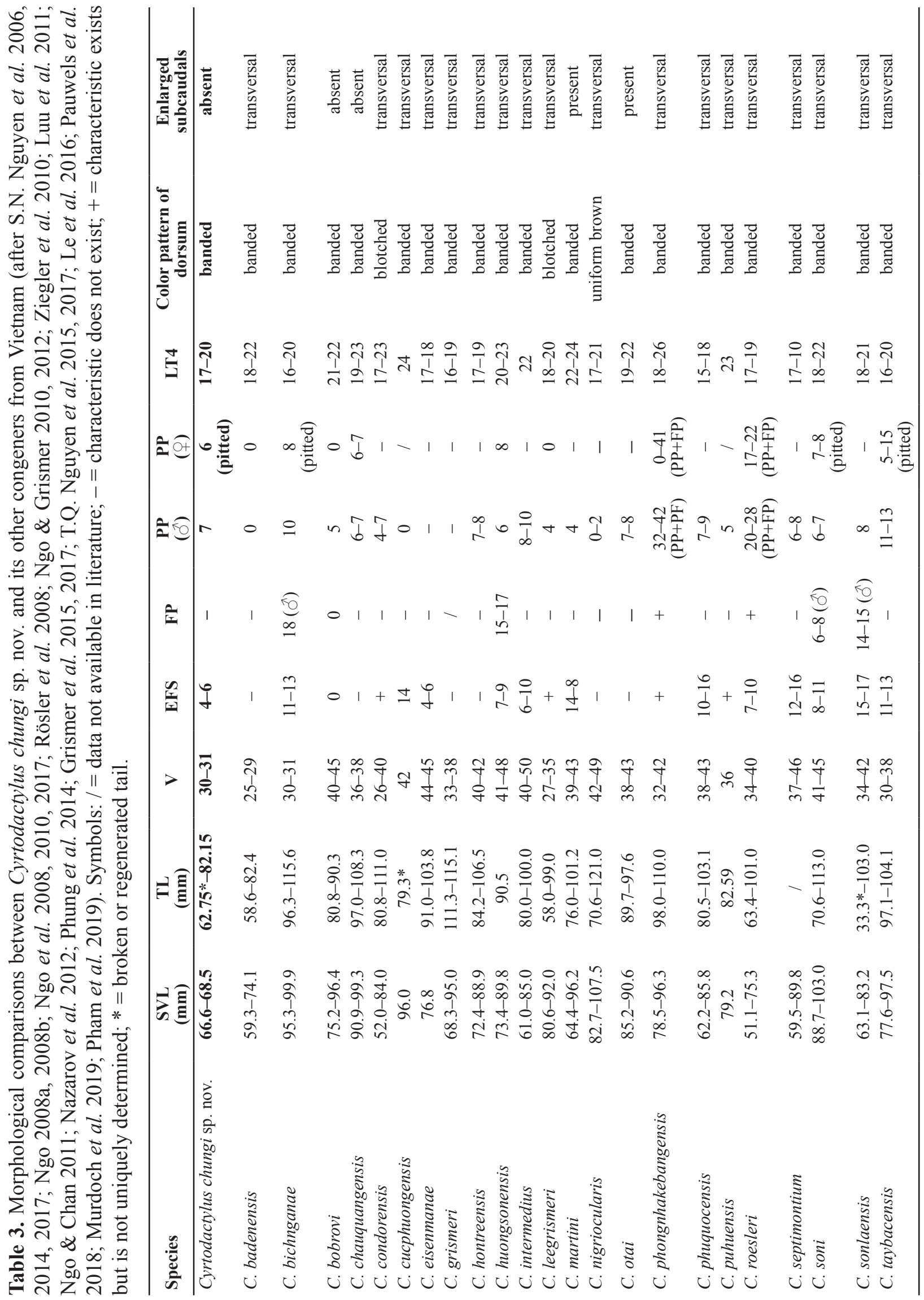




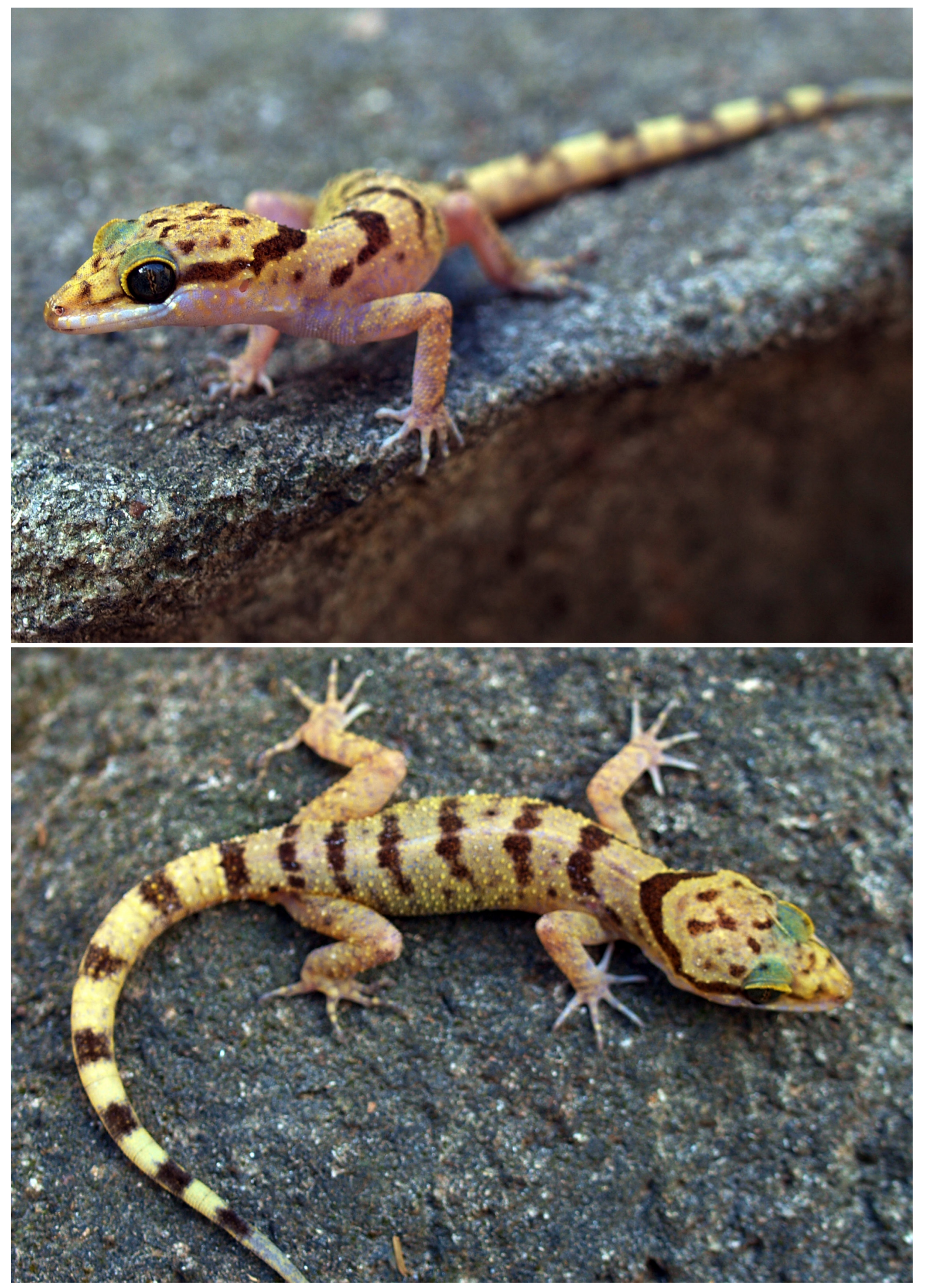

Fig. 4. Cyrtodactylus chungi sp. nov., in life paratype, + (IEBR 4582). Photos T.M. Phung. 

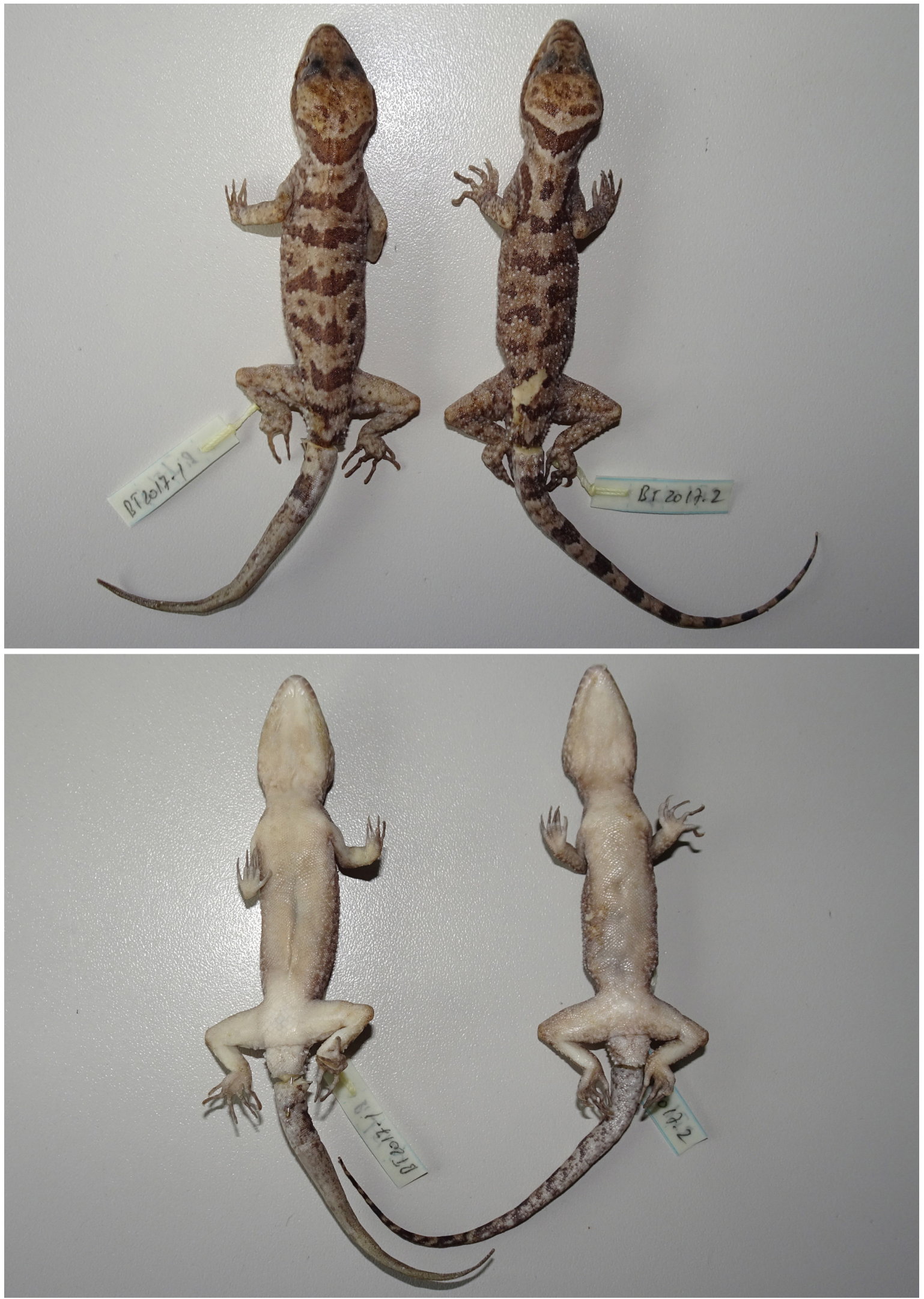

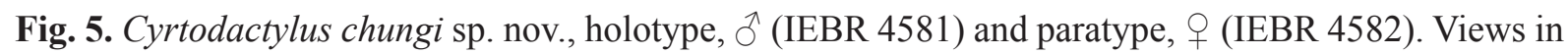
preservative. Top: dorsal view. Bottom: ventral view. Photos T. Ziegler. 
Cyrtodactylus chungi sp. nov. differs from C. cucdongensis Schneider, Phung, Le, Nguyen \& Ziegler, 2014 by its larger size (SVL 66.6-68.5 vs 55.8-65.9 mm), fewer ventral scale rows (30-31 vs 35-44) and enlarged femoral scales (4-6 vs 5-9).

Cyrtodactylus chungi sp. nov. differs from C. dati Ngo, 2013 by having fewer ventral scale rows (30-31 vs 42-48) and by the different dorsal color pattern (irregular transverse bands vs irregular dark blotches).

Cyrtodactylus chungi sp. nov. differs from C. huynhi Ngo \& Bauer, 2008 by having fewer ventral scale rows (30-31 vs 43-46) and by the absence of femoral pores (vs 3-8).

Cyrtodactylus chungi sp. nov. differs from C. irregularis (Smith, 1921) by its smaller size (SVL of 66.6-68.5 vs $72.0-86.0 \mathrm{~mm}$ ), having fewer ventral scale rows (30-31 vs 38-45) and enlarged femoral scales (4-6 vs 7-8), and by the different dorsal color pattern (irregular transverse bands vs transverse bands with uneven margins in white binding, some bands can fall into separated spots).

Cyrtodactylus chungi sp. nov. differs from C. phnomchiensis Neang, Henson \& Stuart, 2020 by its smaller size (SVL 66.6-68.5 vs 76.1-80.7 mm), having fewer ventral scale rows (30-31 vs 45-54) enlarged femoral scales (4-6 vs $0-8$ ), precloacal pores in males ( 7 vs 4-5) and subdigital lamellae under the fourth to (17-20 vs 20-23) and by the different dorsal color pattern (irregular transverse brown bands vs dark brown body bands bordered by yellowish white or light brown bands).

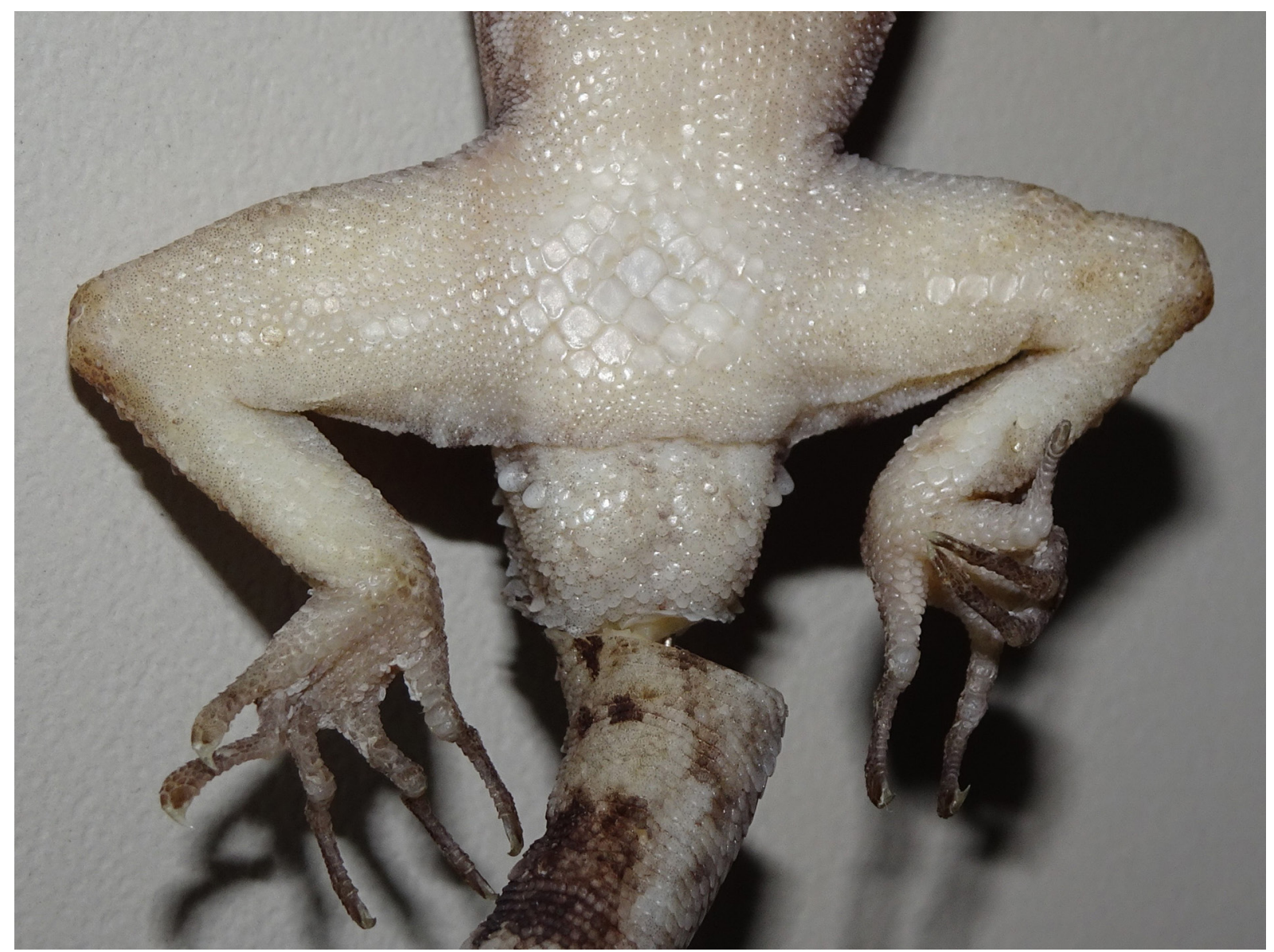

Fig. 6. Cyrtodactylus chungi sp. nov., holotype, $\widehat{\jmath}$ (IEBR 4581). Cloacal region in preservative. Photo T. Ziegler. 
Cyrtodactylus chungi sp. nov. differs from C. phumyensis Ostrowski, Do, Lee, Ngo, Pham, Nguyen, Nguyen \& Ziegler, 2020 by having fewer ventral scale rows (30-31 vs 33-40), the absence of pitted precloacal scales in the male (absent vs 1), more paravertebral tubercles (24-27 vs 20-23) and by the different dorsal color pattern (irregular transverse bands vs anteriorly irregularly spotted and posteriorly banded).

Cyrtodactylus chungi sp. nov. differs from C. phuocbinhensis Nguyen, Le, Tran, Orlov, Lathrop Macculoch, Le, Jin, Nguyen, Nguyen, Hoang, Che, Murphy \& Zhang, 2013 by its larger size (SVL $66.6-68.5 \mathrm{~mm}$ vs $46.0-60.4 \mathrm{~mm}$ ), having fewer ventral scale rows (30-31 vs 43-47), the presence of 6 pitted precloacal scales in the female (vs absence) and the different dorsal color pattern (irregular transversal bands vs stripes).

Cyrtodactylus chungi sp. nov. differs from C. ziegleri Nazarov, Orlov, Nguyen \& Ho, 2008 by its smaller size (SVL of 66.6-68.5 vs 84.6-93.0 mm), having fewer ventral scale rows (30-31 vs 33-39) and enlarged femoral scales (4-6 vs 8-10).

Cyrtodactylus chungi sp. nov. is most similar to C. sangi Pauwels, Nazarov, Bobrov \& Poyarkov, 2018. However, the new species can be distinguished from $C$. sangi by its larger size (SVL 66.6-68.5 vs $49.9-56.3 \mathrm{~mm}$ ), having fewer ventral scale rows ( $30-31$ vs 37 ) and by the different dorsal color pattern (irregular transversal bands with a closed neck band vs irregular transversal bands and pattern with an interrupted neck band).
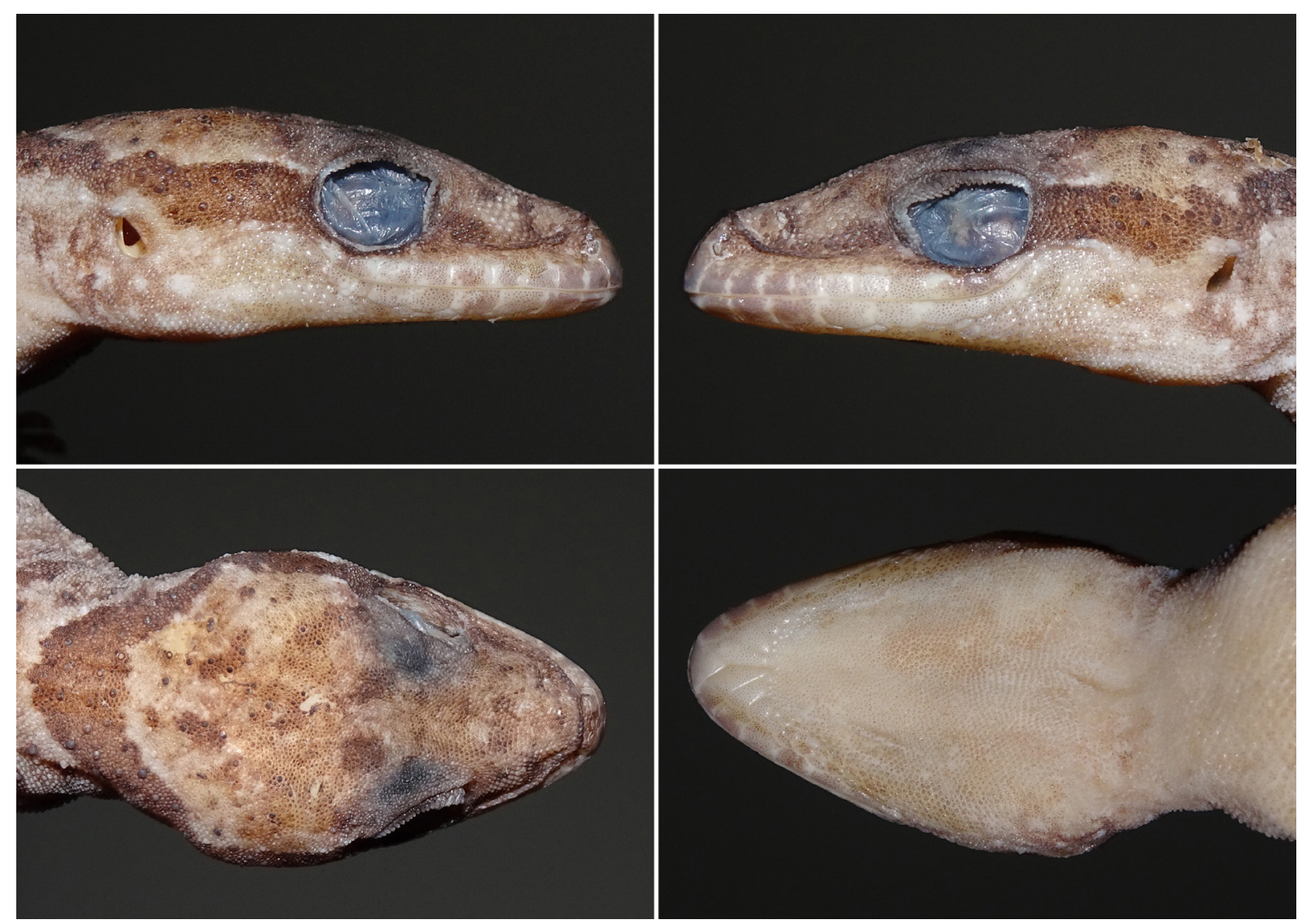

Fig. 7. Head views in preservative of Cyrtodactylus chungi sp. nov. from Ta Kou Nature Reserve, Binh Thuan Province, Vietnam. On the left: holotype, $\widehat{\partial}$ (IEBR 4581); on the right: paratype, $q$ (IEBR 4582). Top: lateral view. Bottom left: dorsal view. Bottom right: ventral view. Photos T. Ziegler. 


\section{Distribution}

Cyrtodactylus chungi sp. nov. is currently known only from the type locality in Ta Kou Nature Reserve, Binh Thuan Province, Vietnam (Fig. 1).

\section{Natural history}

Specimens were found at night between 20:00 and 22:00, on granite rock nearby a forest path, about $0.5-1.0 \mathrm{~m}$ above the ground, at elevations between 400 and $500 \mathrm{~m}$ a.s.1. The surrounding habitat was evergreen forest of medium and small hardwoods mixed with shrubs and vines. The humidity was approximately $68-72 \%$ and the air temperature ranged from 26.8 to $31.6^{\circ} \mathrm{C}$ (Fig. 9).

\section{Discussion}

In our phylogenic analyses, Cyrtodactylus chungi is recovered as the sister taxon to C. cattienensis s. str. with the genetic divergence of more than $9 \%$. Although superficially similar, the new species differs in color pattern and scalation characters. The new species is recovered as a member of the Cyrtodactylus irregularis species group, which consists of C. bidoupimontis Nazarov, Poyarkov, Orlov, Phung, Nguyen, Hoang \& Ziegler, 2012, C. bugiamapensis Nazarov, Poyarkov, Orlov, Phung, Nguyen, Hoang \& Ziegler, 2012, C. caovansungi Orlov, Nguyen, Nazarov, Ananjeva \& Nguyen, 2007, C. cattienensis Geissler, Nazarov, Orlov, Böhme, Phung, Nguyen \& Ziegler, 2009, C. cryptus Heidrich, Rösler, Vu, Böhme \& Ziegler, 2007, C. cucdongensis Schneider, Phung, Le, Nguyen \& Ziegler, 2014, C. dati Ngo, 2013, C. gialaiensis Luu, Dung, Nguyen, Le \& Ziegler, 2017, C. huynhi Ngo \& Bauer, 2008, C. irregularis
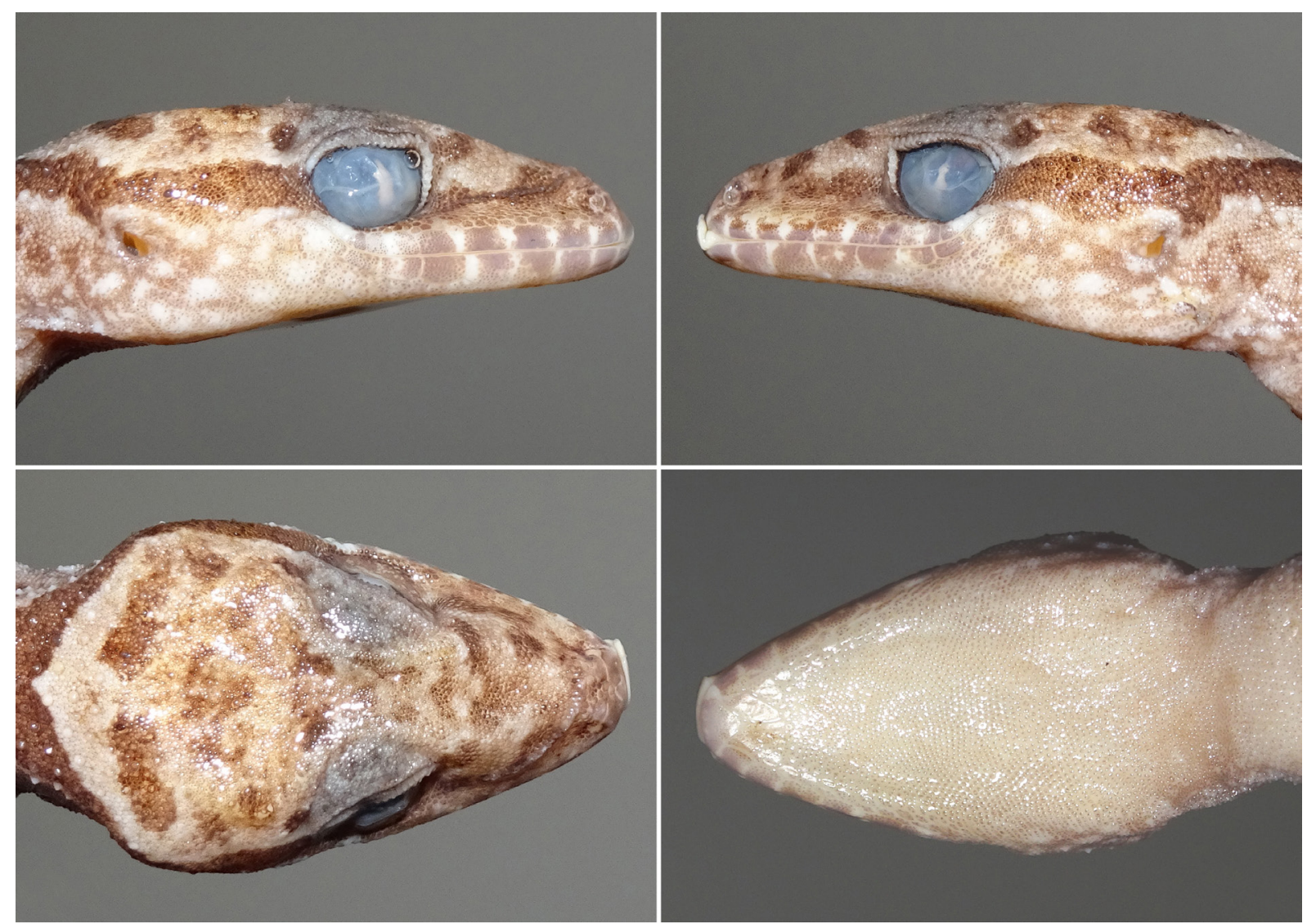

Fig. 8. Cyrtodactylus chungi sp. nov., paratype, $q$ (IEBR 4582). Head views in preservative. Top: lateral view. Bottom left: dorsal view. Bottom right: ventral view. Photos T. Ziegler. 
(Smith, 1921), C. kingsadai Ziegler, Phung, Le \& Nguyen, 2013, C. phnomchiensis Neang, Henson \& Stuart, 2020, C. phumyensis Ostrowski, Do, Lee, Ngo, Pham, Nguyen, Nguyen \& Ziegler, 2020, C. phuocbinhensis Nguyen, Le, Tran, Orlov, Lathrop Macculoch, Le, Jin, Nguyen, Nguyen, Hoang, Che, Murphy \& Zhang, 2013, C. pseudoquadrivirgatus Rösler, Nguyen, Vu, Ngo \& Ziegler, 2008, C. sangi Pauwels, Nazarov, Bobrov \& Poyarkov, 2018, C. takouensis Ngo \& Bauer, 2008, C. taynguyenensis Nguyen, Le, Tran, Orlov, Lathrop Macculoch, Le, Jin, Nguyen, Nguyen, Hoang, Che, Murphy \& Zhang, 2013, C. yangbayensis Ngo \& Chan, 2010 and C. ziegleri Nazarov, Orlov, Nguyen \& Cuc, 2008.

The $C$. irregularis group has been split into a northern C. pseudoquadrivirgatus clade (A), including C. cryptus, C. pseudoquadrivirgatus, C. taynguyenensis, and a southern C. irregularis clade (B), consisting of the remaining taxa, based on two nuclear genes, RPL35 and Rag1 (S.N. Nguyen et al. 2017). C. chungi was found within the distribution of clade B, which is characterized by enlarged femoral scales. However, group A lacks this character. Accordingly, this group is characterized by small femoral scales. Similar to the results based the single mitochondrial COI reported by S.N. Nguyen et al. (2017), our analyses and previous studies based on the same gene have not been able to fully resolve the phylogenetic relationships within the $C$. irregularis group, especially the deep nodes of the phylogeny, although species in the group are highly diverged from each other in terms of genetic distance. In addition, substantial discrepancies between phylogenetic relationships derived from nuclear and mitochondrial markers (see S.N. Nguyen et al. 2017) emphasize the need to include additional molecular data to investigate the complicated evolutionary history of the group. Moreover, the $C$. irregularis species group still includes unsolved taxonomic issues, such as an obvious cryptic taxon sister to C. irregularis and the C. pseudoquadrivirgatus species group apparently containing more than one species.

The new species was discovered in Ta Kou Nature Reserve, Binh Thuan Province, from where C. takouensis was described (Ngo \& Bauer 2008). The latter species, which distinctly differs in morphology (color pattern and scalation) and by genetic divergence (16.4\%), also seems to inhabit a

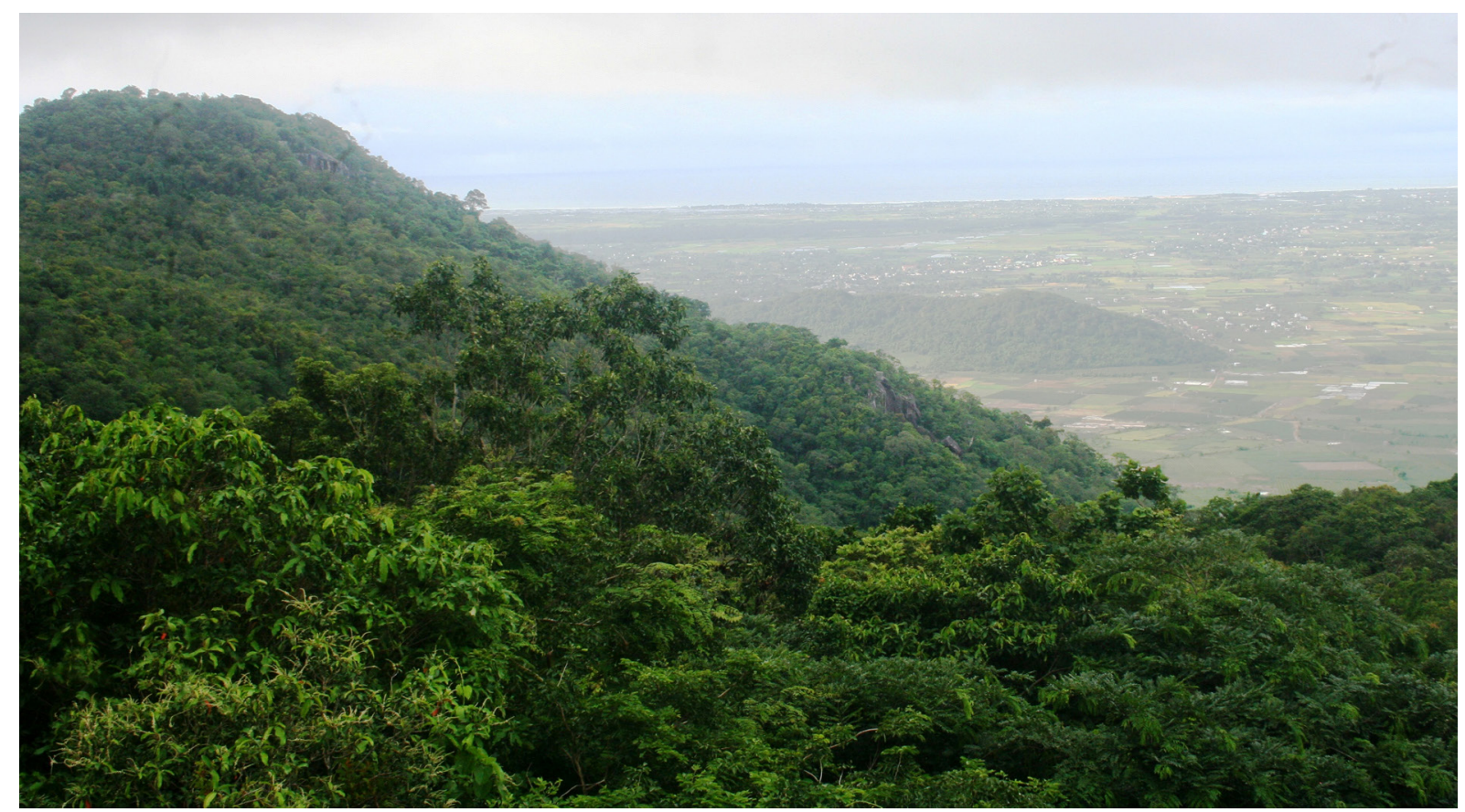

Fig. 9. Habitat of Cyrtodactylus chungi sp. nov. in Ta Kou Nature Reserve, Binh Thuan Province. Photo C.T. Pham. 
different microhabitat, because it was found in a cave in deciduous forest, whereas C. chungi was found on rocks in the evergreen forest.

The Ta Kou Nature Reserve is located in the Binh Thuan Province, coastal southern central of Vietnam. It is like an isolated island on land with endangered species, e.g., Trachypithecus germaini (MilneEdwards, 1876) and Pygathrix nigripes (Milne-Edwards, 1871), and two new species of geckos were discovered, namely Cyrtodactylus takouensis Ngo \& Baur, 2008 and Gekko takouensis Ngo \& Gamble, 2010 (Uetz et al. 2020). A major threat to the local fauna is habitat loss by agricultural extension and tourism development.

\section{Acknowledgments}

We thank A. Rauhaus (Cologne) for arranging the plates and E. Sterling (New York) and K. Koy (Berkeley) for providing the map. Thanks to Lee Grismer (Riverside) and an anonymous reviewer for their helpful comments improving the manuscript. T.M. Phung thanks T.L.T. Nguyen (Binh Duong Province) and L.D. Dinh (Ta Kou Binh Thuan Province) for their assistance in the field.

\section{References}

Geissler P., Nazarov R., Orlov N., Böhme W., Phung T.M., Nguyen T.Q. \& Ziegler T. 2009. A new species of the Cyrtodactylus irregularis complex (Squamata: Gekkonidae) from southern Vietnam. Zootaxa 2161 (1): 20-32. https://doi.org/10.11646/zootaxa.2161.1.2

Grismer L.L., Wood P.L. Jr., Ngo V.T. \& Murdoch M.L. 2015. The systematics and independent evolution of cave ecomorphology in distantly related clades of bent-toed geckos (genus Cyrtodactylus Gray, 1827) from the Mekong Delta and islands in the Gulf of Thailand. Zootaxa 3980 (1): 106-126. https://doi.org/10.11646/zootaxa.3980.1.6

Grismer L.L., Wood P.L. Jr., Thura M.K., Zin T., Quah E.S.H., Murdoch M.L., Grismer M.S., Lin A., Kyaw H. \& Lwin N. 2017. Twelve new species of Cyrtodactylus Gray (Squamata: Gekkonidae) from isolated limestone habitats in east-central and southern Myanmar demonstrate high localized diversity and unprecedented microendemism. Zoological Journal of the Linnean Society 182 (4): 862-959. https://doi.org/10.1093/zoolinnean/zlx057

Grismer L.L., Wood P.L. Jr., Quah E.S.H., Murdoch M.L., Grismer M.S., Herr M.W., Espinoza R.E., Brown R.M. \& Lin A. 2018. A phylogenetic taxonomy of the Cyrtodactylus peguensis group (Reptilia: Squamata: Gekkonidae) with descriptions of two new species from Myanmar. PeerJ 6: e5575. https://doi.org/10.7717/peerj.5575

Heidrich A., Rösler H., Vu T.N., Böhme W. \& Ziegler T. 2007. Another new Cyrtodactylus (Squamata: Gekkonidae) from Phong Nha - Ke Bang National Park, central Truong Son, Vietnam. Zootaxa 1445 (1): 35-48. https://doi.org/10.11646/zootaxa.1445.1.3

Hillis D.M. \& Bull J.J. 1993. An empirical test of bootstrapping as a method for assessing confidence in phylogenetic analysis. Systematic Biology 42: 182-192. https://doi.org/10.1093/sysbio/42.2.182

Ivanova N.V., Dewaard J.R. \& Hebert P.D.N. 2006. An inexpensive, automation-friendly protocol for recovering high-quality DNA. Molecular Ecology Notes 6: 998-1002.

https://doi.org/10.1111/j.1471-8286.2006.01428.x

Le D.T., Nguyen T.Q., Le M.D. \& Ziegler T. 2016. A new species of Cyrtodactylus (Squamata: Gekkonidae) from Ninh Binh Province, Vietnam. Zootaxa 4162 (2): 268-282.

https://doi.org/10.11646/zootaxa.4162.2.4

Luu V.Q., Nguyen T.Q., Do H.Q. \& Ziegler T. 2011. A new Cyrtodactylus (Squamata: Gekkonidae) from Huong Son limestone forest, Hanoi, northern Vietnam. Zootaxa 3129 (1): 39-50.

https://doi.org/10.11646/zootaxa.3129.1.3 
Luu V.Q., Bonkowski M., Nguyen T.Q., Le M.D., Schneider N., Ngo H.T. \& Ziegler T. 2016. Evolution in karst massifs: cryptic diversity among bent-toed geckos along the Truong Son Range with descriptions of three new species and one new country record from Laos. Zootaxa 4107 (2): 101-140.

https://doi.org/10.11646/zootaxa.4107.2.1

Luu V.Q., Tran D.V., Nguyen T.Q., Le M.D. \& Ziegler T. 2017. A new species of the Cyrtodactylus irregularis complex (Squamata: Gekkonidae) from Gia Lai Province, Central Highlands of Vietnam. Zootaxa 4362 (3): 385-404. https://doi.org/10.11646/zootaxa.4362.3.4

Murdoch M.L., Grismer L.L., Wood P.L. Jr., Neang T., Poyarkov N.A., Ngo V.T., Nazarov R.A., Aowphol A., Pauwels O.S.G., Nguyen H.N. \& Grismer J.L. 2019. Six new species of the Cyrtodactylus intermedius complex (Squamata: Gekkonidae) from the Cardamom Mountains and associated highlands of Southeast Asia. Zootaxa 4554 (1): 1-62. https://doi.org/10.11646/zootaxa.4554.1.1

Nazarov R.A., Orlov N.L., Nguyen N.S. \& Ho T.C. 2008. Taxonomy of naked-toes geckos Cyrtodactylus irregularis complex of south Vietnam and description of a new species from Chu Yang Sin Natural Park (Krong Bong district, Dac Lac province, Vietnam). Russian Journal of Herpetology 15 (2):141-156.

Nazarov R., Poyarkov N.A., Orlov N.L., Phung T.M., Nguyen T.T., Hoang D.M. \& Ziegler T. 2012. Two new cryptic species of the Cyrtodactylus irregularis complex (Squamata: Gekkonidae) from southern Vietnam. Zootaxa 3302 (1): 1-24. https://doi.org/10.11646/zootaxa.3302.1.1

Neang T., Henson A. \& Stuart B.L. 2020. A new species of Cyrtodactylus (Squamata, Gekkonidae) from Cambodia's Prey Lang Wildlife Sanctuary. ZooKeys 926: 133-158.

https://doi.org/10.3897/zookeys.926.48671

Ngo T.V. 2008a. Two new cave-dwelling species of Cyrtodactylus Gray (Squamata: Gekkonidae) from Southwestern Vietnam. Zootaxa 1909 (1): 37-51. https://doi.org/10.11646/zootaxa.1909.1.4

Ngo T.V. 2008b. Cyrtodactylus martini, another new karst-dwelling Cyrtodactylus Gray, 1827 (Squamata: Gekkonidae) from Northwestern Vietnam. Zootaxa 2834 (1): 33-46.

https://doi.org/10.11646/zootaxa.2834.1.3

Ngo T.V. 2013. Cyrtodactylus dati, a new forest dwelling bent-toed gecko (Squamata: Gekkonidae) from southern Vietnam. Zootaxa 3616 (2): 151-164. https://doi.org/10.11646/zootaxa.3616.2.4

Ngo T.V. \& Bauer A.M. 2008. Descriptions of two new species of Cyrtodactylus Gray, 1827 (Squamata: Gekkonidae) endemic to southern Vietnam. Zootaxa 1715 (1): $27-42$.

https://doi.org/10.11646/zootaxa.1715.1.2

Ngo T.V. \& Chan K.O. 2010. A new species of Cyrtodactylus Gray, 1826 (Squamata: Gekkonidae) from Khanh Hoa province, Southern Vietnam. Zootaxa 2504 (1): 47-60.

https://doi.org/10.11646/zootaxa.2504.1.4

Ngo T.V. \& Chan K.O. 2011. A new karstic cave-dwelling Cyrtodactylus Gray (Squamata: Gekkonidae) from Northern Vietnam. Zootaxa 3125 (1): 51-63. https://doi.org/10.11646/zootaxa.3125.1.4

Ngo T.V. \& Grismer L.L. 2010. A new karst dwelling Cyrtodactylus (Squamata: Gekkonidae) from Son La Province, northwestern Vietnam. Hamadryad 35: 84-95. https://doi.org/10.11646/zootaxa.3835.1.4

Ngo T.V. \& Grismer L.L. 2012. A new endemic species of Cyrtodactylus Gray (Squamata: Gekkonidae) from Tho Chu Island, southwestern Vietnam. Zootaxa 3228 (1): 48-60.

https://doi.org/10.11646/zootaxa.3228.1.2

Ngo T.V., Grismer L.L. \& Grismer J.L. 2008. A new endemic cave dwelling species of Cyrtodactylus Gray, 1827 (Squamata: Gekkonidae) in Kien Giang Biosphere Reserve, Southwestern Vietnam. Zootaxa 1967 (1): 53-62. https://doi.org/10.11646/zootaxa.1967.1.3 
Ngo T.V., Grismer L.L. \& Grismer J.L. 2010. A new species of Cyrtodactylus Gray, 1827 (Squamata: Gekkonidae) in Phu Quoc National Park, Kien Giang Biosphere Reserve, Southwestern Vietnam. Zootaxa 2604 (1): 37-51. https://doi.org/10.11646/zootaxa.2604.1.3

Ngo H.T., Le M.D., Pham N.D., Nguyen V.T.H., Pham C.T. \& Nguyen T.Q. 2017. Taxonomy and phylogenetic relationships of Cyrtodactylus (Squamata: Gekkonidae) in Vietnam. VNU Journal of Science: Natural Sciences and Technology 33 (1S): 182-192.

https://doi.org/10.25073/2588-1140/vnunst.4530

Nguyen S.N., Orlov N.L. \& Darevsky S.I. 2006. Descriptions of two new species of the genus Cyrtodactylus Gray, 1827 (Squamata: Sauria: Gekkonidae) from Southern Vietnam. Russian Journal of Herpetology 13 (3): 215-226.

Nguyen S.N., Le T.T., Tran T.A.D., Orlov N.L., Lathrop A., Macculloch R.D., Le T.T., Jin J., Nguyen L.T., Nguyen T.T., Hoang D.D., Che J., Murphy R.W. \& Zhang Y.-P. 2013. Phylogeny of the Cyrtodactylus irregularis species complex (Squamata: Gekkonidae) from Vietnam with the description of two new species. Zootaxa 3737 (4): 399-414. https://doi.org/10.11646/zootaxa.3737.4.4

Nguyen S.N., Yang J-X., Le N.T.T., Nguyen L.T., Orlov N.L., Hoang C.V., Nguyen T.Q., Jin J-Q., Rao D-Q., Hoang T.N., Che J., Murphy R.W. \& Zhang Y.-P. 2014. DNA barcoding of Vietnamese benttoed geckos (Squamata: Gekkonidae: Cyrtodactylus) and the description of a new species. Zootaxa 3784 (1): 48-66. https://doi.org/10.11646/zootaxa.3784.1.2

Nguyen S.N., Zhou W.-W., Le T.-N.T., TranA.-D.T., Jin J.-Q., Vo B.D., Nguyen L.T. Nguyen T.T., Nguyen T.Q., Hoang D.D., Orlov N.L., Che J., Murphy R.W. \& Zhang Y.-P. 2017. Cytonuclear discordance, cryptic diverity, complex histories and conversation needs on vietnamese bent-toed geckos of the Cyrtodactylus irregularis complex. Russian Journal of Herpetology 24 (2): 133-154.

Nguyen T.Q., Le M.D., Pham A.V., Ngo H.N., Hoang C.V., Pham C.T. \& Ziegler T. 2015. Two new species of Cyrtodactylus (Squamata: Gekkonidae) from the karst forest of Hoa Binh Province, Vietnam. Zootaxa 3985 (3): 375-390. https://doi.org./zootaxa.3985.3.3

Nguyen T.Q, Pham A.V., Ziegler T., Ngo H.T. \& Le M.D. 2017. A new species of Cyrtodactylus (Squamata: Gekkonidae) and the first record of C. otai from Son La Province, Vietnam. Zootaxa 4341 (1): 25-40. https://doi.org/10.11646/zootaxa.4341.1.2

Orlov N.L., Nguyen Q.T., Nazarov R.A., Anajeva N.B. \& Nguyen S.N. 2007. A new species of the genus Cyrtodactylus Gray, 1827 and redescription of Cyrtodactylus paradoxus (Darevsky et Szczerbak, 1997) [Squamata: Sauria: Gekkonidae] from South Vietnam. Russian Journal of Herpetology 14 (2): 145-152.

Ostrowski S., Do D.T, Le M.D., Ngo H.T., Pham C.T., Nguyen T.Q., Nguyen V.T. \& Ziegler T. 2020. A new species of Cyrtodactylus (Squamata: Gekkonidae) from southern Vietnam. Zootaxa 4789 (1): 171-203. https://doi.org/10.11646/zootaxa.4789.1.5

Pauwels O.S.G., Nazarov R.A., Bobrov V.V. \& Poyarkov N.A. 2018. Taxonomic status of two populations of bent-toed geckos of the Cyrtodactylus irregularis complex (Squamata: Gekkonidae) with description of a new species from Nui Chua National Park, southern Vietnam. Zootaxa 4403 (2): 307-335.

https://doi.org/10.11646/zootaxa.4403.2.5

Pham A.V, Le M.D., Ngo H.T., Ziegler T. \& Nguyen T.Q. 2019. A new species of Cyrtodactylus (Squamata: Gekkonidae) from northwestern Vietnam. Zootaxa 4544 (1): 360-380.

https://doi.org/10.11646/zootaxa.4544.3.3

Phung T.M., van Schingen M., Ziegler T. \& Nguyen T.Q. 2014. A third new Cyrtodactylus (Squamata: Gekkonidae) from Ba Den Mountain, Tay Ninh Province, southern Vietnam. Zootaxa 3764 (3): 347 363. http://dx.doi.org/10.11646/zootaxa.3764.3.5 
Posada D. \& Crandall K.A. 1998. MODELTEST: testing the model of DNA substitution. Bioinformatics 14: 817-818. https://doi.org/10.1093/bioinformatics/14.9.817

Ronquist F., Teslenko M., van der Mark P., Ayres D.L., Darling A., Höhna S., Larget B., Liu L., Suchard M.A. \& Huelsenbeck J.P. 2012. MrBayes 3.2: efficient Bayesian phylogenetic inference and model choice across a large model space. Systematic Biology 61: 539-542.

https://doi.org/10.1093/sysbio/sys029

Rösler H., Ngoc T.V., Nguyen T.Q., Ngo V.T. \& Ziegler T. 2008. A new Cyrtodactylus (Squamata: Gekkonidae) from Central Vietnam. Hamadryad 33 (1): 48-63.

Schneider N., Phung T.M., Le M.D., Nguyen T.Q. \& Ziegler T. 2014. A new Cyrtodactylus (Squamata: Gekkonidae) from Khanh Hoa Province, southern Vietnam. Zootaxa 3785 (4): 518-532.

https://doi.org/10.11646/zootaxa.3785.4.2

Simmons J.E. 2002. Herpetological Collecting and Collections Management. Revised edition. Herpetological Circular 31: 1-153. Society for the Study of Amphibians and Reptiles.

Smith M.A. 1921a. New or little-known reptiles and batrachians from Southern Annam (Indo-China). Proceedings of the Zoological Society of London 91 (2): 423-440.

https://doi.org/10.1111/j.1096-3642.1921.tb03271.x

Smith M.A. 1921b. Reptiles and batrachians collected on Pulo Condore. The Journal of the Natural History Society of Siam 4 [1920]: 93-97.

Available from https://www.biodiversitylibrary.org/part/75704\#/summary [accessed 21 Nov. 2020].

Swofford D. 2002. PAUP*. Phylogenetic Analysis Using Parsimony (*and Other Methods). Version 4.0b10. Sinauer, Sunderland, MA.

Thompson J.D., Gibson T.J., Plewniak F., Jeanmougin F. \& Higgins D.G. 1997. The Clustal_X windows interface: flexible strategies for multiple sequence alignment aided by quality analysis tools. Nucleic Acids Research 25: 4876-4882. https://doi.org/10.1093/nar/25.24.4876

Uetz P., Freed P. \& Hošek J. (eds) 2020. The Reptile Database.

Available from: http://www.reptile-database.org [accessed 14 Sep. 2020].

Ziegler T., Rösler H., Herrmann H.-W. \& Vu T.N. 2002. Cyrtodactylus phongnhakebangensis sp. n., ein neuer Bogenfingergecko aus dem annamitischen Karstwaldmassiv, Vietnam. Herpetofauna 24: 11-25.

Ziegler T., Nazarov R., Orlov N., Nguyen T.Q., Vu T.N., Dang K.N., Dinh T.H. \& Schmitz A. 2010. A third new Cyrtodactylus (Squamata: Gekkonidae) from Phong Nha-Ke Bang National Park, Vietnam. Zootaxa 2413 (1): 20-36. https://doi.org/10.11646/zootaxa.2413.1.2

Ziegler T., Phung T.M., Le M.D. \& Nguyen T.Q. 2013. A new Cyrtodactylus (Squamata: Gekkonidae) from Phu Yen Province, southern Vietnam. Zootaxa 3686 (4): 432-446.

https://doi.org/10.11646/zootaxa.3686.4.2

Manuscript received: 11 March 2020

Manuscript accepted: 24 September 2020

Published on: 13 January 2021

Topic editor: Rudy Jocqué

Desk editor: Pepe Fernández 
Printed versions of all papers are also deposited in the libraries of the institutes that are members of the EJT consortium: Muséum national d'histoire naturelle, Paris, France; Meise Botanic Garden, Belgium; Royal Museum for Central Africa, Tervuren, Belgium; Royal Belgian Institute of Natural Sciences, Brussels, Belgium; Natural History Museum of Denmark, Copenhagen, Denmark; Naturalis Biodiversity Center, Leiden, the Netherlands; Museo Nacional de Ciencias Naturales-CSIC, Madrid, Spain; Real Jardín Botánico de Madrid CSIC, Spain; Zoological Research Museum Alexander Koenig, Bonn, Germany; National Museum, Prague, Czech Republic.

\section{Supplementary material}

Supplementary file 1. Distance matrix. https://doi.org/10.5852/ejt.2021.731.1203.3403 